\title{
Advanced characterization for industrial catalysis applications
}

\author{
Shelly Kelly †, Wharton Sinkler †, Lijun Xu, Sergio Sanchez, Cem Akatay, Haiyan Wang, \\ John Qianjun Chen * \\ Honeywell UOP, 25 E Algonquin Road, Des Plaines, IL 60016, Unites States of America
}

\section{A R T I C L E I N F O}

Article history:

Received 31 January 2019

Accepted 28 March 2019

Published 5 November 2019

\section{Keywords:}

Catalysis fundamental

Platinum

Metal sulfides

Catalytic reforming

Hydroprocessing

\begin{abstract}
A B S T R A C T
The interplay between analytical technique and industrial practice has been central in the development of catalytic materials for processing petroleum. This article presents reviews of key aspects of two of the most important classes of catalytic materials: noble-metal Pt nanoparticles (NPs) on alumina, which are the basis of catalytic reforming; and layered sulfides of Mo and W, which catalyze hydrogenation and hetero-atom removal in hydroprocessing. The state of understanding of Pt cluster growth and resulting structures, as developed using X-ray absorption spectroscopy and STEM, is reviewed. Influences of both Pt reduction temperature in hydrogen gas, and oxidizing pretreatment conditions prior to Pt reduction, are considered. Recent work by the present authors on Pt NP structure evolution is presented in the context of the previous work. A review is subsequently presented of layered sulfide based NPs, summarizing contributions from a range of analytical techniques. Work on active site structures of sulfide NPs is reviewed, focusing particularly on the critical interactions of active edge sites with sulfur and hydrogen in chemisorption, physisorption, and spillover interactions. New temperature programmed reduction (TPR) results are presented for supported and unsupported sulfide NPs. Structural changes in TPR of alumina-supported $\mathrm{MoS}_{2}$ are investigated using extended X-ray absorption fine structure and density functional theory modeling, and are determined to arise from removal of identifiable edge-site sulfur species.
\end{abstract}

(C) 2019, Dalian Institute of Chemical Physics, Chinese Academy of Sciences. Published by Elsevier B.V. All rights reserved.

\section{Introduction}

The earliest known oil wells were drilled in China in $347 \mathrm{AD}$ or earlier. In 1859, petroleum became a major industry following the drill and discovery of oil at Oil Creek Pennsylvania. Today, crude oil is refined all over the world. Nearly every aspect of our modern lifestyle is impacted by oil. Oil is used to power our vehicles and planes, to produce electricity, to make the plastics, cosmetics, and to create medicines that keep us healthy.

In early refining processes, simple distillation was used to produce gasoline, kerosene and other fuels from crude oil. Beginning in the 1930s, under the direction of Vladimir Ipatieff,
Honeywell UOP developed the process of catalytic condensation using SPA - solid phosphoric acid - to produce polymer gasoline and gasoline blending components. The pioneering work marked the birth of petroleum catalysis age. The use of catalysts has given mankind much greater control of reaction rates and conversion selectivity. Today, catalysts are at the heart of virtually all refining and petrochemical processes.

Catalysts design and development is challenging and has benefited greatly from advancement of modern analytical and characterization tools. Molecular modeling has also become more mature and more relevant in aiding solving real world catalysis problems. This paper will review some recent progress in platinum and metal-sulfides based catalysts used in

\footnotetext{
* Corresponding author.E-mail: Qianjun.Chen@Honeywell.com +Contributed equally to this manuscript. DOI: S1872-2067(19)63372-3 | http://www.sciencedirect.com/science/journal/18722067 | Chin. J. Catal., Vol. 40, No. 11, November 2019
} 
today's important refining and petrochemical processes to illustrate the importance of advanced characterization tools for industrial catalysis.

\section{Fundamentals of platinum for catalytic reforming}

Catalytic reforming converts low-octane hydrocarbons in the naphtha range with 5-12 carbon atoms to more valuable high-octane hydrocarbons for gasoline blending and aromatic complexes. The first naphtha reforming catalyst, Pt on chlorided $\gamma-\mathrm{Al}_{2} \mathrm{O}_{3}$, was invented by Vladimir Haensel and patented by UOP in 1949. The operating conditions for catalytic reforming units generally fall within the temperature range of 315 to $537^{\circ} \mathrm{C}, 50$ to 1000 pounds and 0.5 to 10 hourly space velocity $[1,2]$. The reforming catalyst is bifunctional with Pt serving the role of hydrogen transfer for hydrogenation/dehydrogenation and the alumina providing acid sites required for hydrocarbon ring opening/closing. An increasingly important byproduct of catalytic reforming is the production of hydrogen $[3,4]$.

The nature of $\mathrm{Pt}$ and its effect on catalytic performance has been the focus of many studies and reviews [5-8]. The most active catalyst is characterized by small metallic Pt clusters well dispersed on high surface area support of chloride $\gamma-\mathrm{Al}_{2} \mathrm{O}_{3}$. The size, shape, and dispersion of Pt clusters is affected by the preparation methods and operating conditions. Typical reforming catalyst preparation involves the wet impregnation of the high surface area $\gamma-\mathrm{Al}_{2} \mathrm{O}_{3}$ with an aqueous solution containing platinum salt or organic acid. The catalyst is often dried and/or calcined followed by a reduction treatment in $\mathrm{H}_{2}$ gas to reduce the Pt and form small clusters. One common and long used characterization tool used to determine the Pt cluster size and dispersion is the measurement of hydrogen chemisorption $[9,10]$. Before 1980, direct measurement of such small particles was not possible such that correlations between hydrogen chemisorption and X-ray diffraction (XRD) were made only on large agglomerated clusters. Even so, through careful measurements $\mathrm{H}_{2} / \mathrm{Pt}$ ratios of one or even slightly larger than one [11] are found for highly dispersed Pt clusters with sizes of less than $10 \AA$.

Chemisorption measurements have shown two regions for hydrogen uptake on $\mathrm{Pt} / \mathrm{Al}_{2} \mathrm{O}_{3}$ catalyst [8]. Both types of hydrogen, investigated by extended X-ray absorption fine structure (EXAFS), have been found to be chemisorbed but with uniquely different bond lengths. A short strong hydrogen bond forms at high temperature [12]. This strongly bound hydrogen can act as a poison for catalytic activity much like chloride [13] and sulfur [14]. Hydrogenolysis activity decreases after reduction at temperature greater than $550{ }^{\circ} \mathrm{C}$ in hydrogen, and has been attributed to this strongly adsorbed $\mathrm{H}_{2}[15,16]$. In addition, hydrogen chemisorption decreases for $\mathrm{Pt} / \mathrm{Al}_{2} \mathrm{O}_{3}$ catalyst after high temperature reduction [17]. Similarly, chemisorbed hydrogen mobility has been identified as strongly influencing the selectivity for $n$-hexane conversion to benzene [18]. There is a suggestion that the high temperature treatment can result in the formation of a Pt-Al, alloy [19] and/or change the Pt cluster morphology causing the $\mathrm{Pt}$ clusters to become biplanar [20-24]. The platinum clusters are dramatically affected by adsorbed $\mathrm{H}, \mathrm{OH}$, and $\mathrm{Cl}[25,26]$, even the partial pressure of $\mathrm{H}_{2}$ at room temperature has been shown to change the particle morphology [27]. In addition to the hydrogen affecting the particle morphology, the Pt cluster nanoparticle (NP) shape giving rise to high-index facets has appeared to increase catalytic activity for electro-oxidation of formic acid and ethanol compared to spherical NP [28].

Beginning in the 1980s, X-ray absorption spectroscopy (XAS) has been key to understanding the formation and morphology of Pt clusters under in-situ conditions. XAS measurements have primarily been made in-situ on samples that have been treated without air exposure, which is critical to preserving the reduced nature of highly-dispersed Pt clusters. In-situ measurements are one step closer to the more recent development of operando measurements collected under operating conditions matching temperature, pressure and feed during catalysis. Later, electron microscopy techniques have also contributed to our understanding of Pt cluster size and morphology. The development of aberration corrected scanning transmission electron microscopy (AC-STEM) imaging allows individual $\mathrm{Pt}$ atoms to be visualized within small clusters on $\gamma-\mathrm{Al}_{2} \mathrm{O}_{3}$ support. Finally, modeling with density functional theory (DFT) has brought together many different aspects, which brings clarity to many previous experimental results.

The next section starts with a review of Pt cluster formation on $\gamma-\mathrm{Al}_{2} \mathrm{O}_{3}$. A brief description of the samples and results for the studies discussed in detail are listed in Table 1 . Pt cluster attributes are highly affected by the surface of $\gamma-\mathrm{Al}_{2} \mathrm{O}_{3}$ support. $\gamma-\mathrm{Al}_{2} \mathrm{O}_{3}$ is a complicated highly disordered material that has been the subject of many studies [29-32], but is outside the scope of this review except in the most general sense of describing the surface as this is shown to have a direct affected on Pt clusters. Attention is given to the effects of pretreatments such as low temperature drying, high temperature calcination, the formation of Pt clusters through the reduction process by gas phase $\mathrm{H}_{2}$ at different temperatures, and the final Pt morphology of low wt $\%$ Pt on high surface area $\gamma-\mathrm{Al}_{2} \mathrm{O}_{3}$ support.

\subsection{Review of platinum nanoparticles for catalysis}

As early as 1980 it was demonstrated that extended X-ray absorption fine structure (EXAFS) spectroscopy could be used to study the morphology $[21,35]$ of supported metal catalysts. The 1 wt\% Pt on alumina catalyst [36] was prepared by impregnation of chloroplatinic acid (CPA) on $\beta$-alumina trihydrate calcined at $600{ }^{\circ} \mathrm{C}$ for $4 \mathrm{~h}$ and then dried at $110{ }^{\circ} \mathrm{C}$ followed by $\mathrm{H}_{2}$ reduction at $500{ }^{\circ} \mathrm{C}$. Prior to EXAFS measurements the samples were re-reduced in-situ at $425^{\circ} \mathrm{C}$ in $\mathrm{H}_{2}$, with quick cooling to $-173{ }^{\circ} \mathrm{C}$ to increase the signal to noise ratio in the measured spectra. Via et al. [36] showed the Pt clusters on the support were small with large disorder compared to bulk Pt metal. The average Pt coordination number (CN) measured by EXAFS was reduced compared to bulk due to the high percentage of under coordinated Pt atoms at the surface of small clusters. For small clusters, surface atoms contributed significantly to the average, whereas for large particles they were only minor components. Additional evidence for well dispersed Pt clusters was provided 
Table 1

A brief description of samples and results.

\begin{tabular}{|c|c|c|c|c|c|c|}
\hline $\begin{array}{l}\text { Pt loading } \\
\text { and precur- } \\
\text { sor }\end{array}$ & $\begin{array}{l}\text { Alumina and } \\
\text { surface area }\end{array}$ & $\begin{array}{l}\text { Calcination/ } \\
\text { drying }\end{array}$ & Reduction & $\begin{array}{l}\text { In-situ treatment and condi- } \\
\text { tions of XAS measurements }\end{array}$ & XAS results & Ref. \\
\hline $\begin{array}{l}1 \mathrm{wt} \% \text { Pt by } \\
\text { impregna- } \\
\text { tion of chlo- } \\
\text { roplatinic } \\
\text { acid }\end{array}$ & $\begin{array}{l}\beta \text {-alumina trihy- } \\
\text { drate heated at } \\
600^{\circ} \mathrm{C} \text { for } 4 \mathrm{~h} \text {, } \\
\text { surface area } 200 \\
\mathrm{~m}^{2} / \mathrm{g} \\
\end{array}$ & $\begin{array}{l}\text { Calcined at } \\
600^{\circ} \mathrm{C} \text { for } 4 \\
\mathrm{~h}\end{array}$ & $\begin{array}{l}\text { Dried at } \\
110^{\circ} \mathrm{C} \text { fol- } \\
\text { lowed by } \\
\text { reduction in } \\
\mathrm{H}_{2} \text { at } 500^{\circ} \mathrm{C}\end{array}$ & $\begin{array}{c}\text { In-situ re-reduction in } \mathrm{H}_{2} \text { at } \\
425^{\circ} \mathrm{C} \text {. Measurements at } \\
100^{\circ} \mathrm{C} \text { in } \mathrm{H}_{2} .\end{array}$ & $\begin{array}{l}\text { Small Pt clusters compared to bulk with increased } \\
\text { disorder. Some clusters with biplanar morphology. }\end{array}$ & {$[20,29]$} \\
\hline $\begin{array}{l}2 \text { wt } \% \mathrm{Pt} \\
\text { and } 2 \mathrm{wt} \% \\
\mathrm{Cl} \text { from } \\
\text { impregna- } \\
\text { tion of plati- } \\
\text { num hexa- } \\
\text { chloride }\end{array}$ & $\begin{array}{c}\gamma-\mathrm{Al}_{2} \mathrm{O}_{3} \\
\text { surface area } 240 \\
\mathrm{~m}^{2} / \mathrm{g}\end{array}$ & $\begin{array}{c}\text { Dried in air } \\
\text { Dat } 120^{\circ} \mathrm{C} \text { for } \\
12 \mathrm{~h}\end{array}$ & None & $\begin{array}{l}\text { As received spectrum followed } \\
\text { by in-situ isothermal hold at } \\
180^{\circ} \mathrm{C} \text { for three hours. } \\
\text { Initial isothermal hold at } \\
\qquad 180^{\circ} \mathrm{C} \text {. } \\
\text { Final isothermal hold at } 180^{\circ} \mathrm{C} \text {. }\end{array}$ & $\begin{array}{l}\text { As Received spectrum mixed oxychloride species. } \\
\text { Dominated by Pt-Cl. } \\
\text { Incipient clusters showed two Pt-Pt bond lengths. } \\
\text { PtCl CN decreases before Pt-Pt CN increases. } \\
\text { After bnger reduction times Pt-Pt CN increases with } \\
\text { constant Pt-O CN suggesting biplanar morphobgy }\end{array}$ & [33] \\
\hline \multirow[t]{3}{*}{$\begin{array}{l}1 \text { wt } \% \text { Pt } \\
\text { from incipi- } \\
\text { ent wetness } \\
\text { of } \\
{\left[\mathrm{Pt}\left(\mathrm{NH}_{3}\right)_{4}\right](\mathrm{O}} \\
\mathrm{H})_{2}\end{array}$} & $\begin{array}{l}\gamma-\mathrm{Al}_{2} \mathrm{O}_{3}, \text { Ketjen } \\
\text { CK-300 surface } \\
\text { area } 200 \mathrm{~m}^{2} / \mathrm{g}\end{array}$ & $\begin{array}{l}\text { Dried in air } \\
\text { at } 120^{\circ} \mathrm{C} \text { for } \\
15 \mathrm{~h}\end{array}$ & None & $\begin{array}{l}\text { In-situ dried in } \mathrm{He} \text { at } 120^{\circ} \mathrm{C} \text { for } \\
15 \text { min followed by } \mathrm{H}_{2} \text { treat- } \\
\text { ment at } 180^{\circ} \mathrm{C} \text { followed by } \mathrm{H}_{2} \\
\text { treatment at } 200^{\circ} \mathrm{C} \text { and finally } \\
\mathrm{H}_{2} \text { treatment at } 350^{\circ} \mathrm{C} \text { for } 30 \\
\text { min (DECH350). Measure- } \\
\text { ments at RT in } \mathrm{H}_{2} \text {. }\end{array}$ & $\begin{array}{l}\text { Small spherical clusters with } 13 \AA \text { A diameters. } \\
\text { PtPt1 CN } 7.2 \pm 0.3 \text { with distance of } 2.770 \pm 0.004 \\
\text { Ang. Pt-Pt2 CN } 2.8 \pm 1.5 \text { with distance of } 3.90 \pm 0.04 \text {. } \\
\text { Pt-Pt3 and PtPt4 are also listed. }\end{array}$ & [34] \\
\hline & & $\begin{array}{l}\text { Dried in air } \\
\text { at } 120^{\circ} \mathrm{C} \text { for } \\
15 \mathrm{~h}\end{array}$ & None & $\begin{array}{l}\text { In-situ direct reduction in } \mathrm{H}_{2} \text { at } \\
350^{\circ} \mathrm{C} \text { for } 1 \mathrm{~h}(\mathrm{R} 350) \\
\text { Measurements at RT in } \mathrm{H}_{2} \text {. }\end{array}$ & $\begin{array}{c}\text { Large biplanar clusters with } \sim 35 \AA \text { diameters and } \sim 4 \\
\text { layers. Pt-Pt1 CN } 10.1 \pm 0.2 \text { with distance of } 2.771 \pm \\
0.001 \text { Å. Pt-Pt2 CN } 4.4 \pm 0.5 \text { with distance of } 3.93 \pm \\
0.01 \text { Å. Pt-Pt3 and Pt-Pt4 are also listed. }\end{array}$ & \\
\hline & & $\begin{array}{l}\text { Calcined in } \\
\text { air at } 3500^{\circ} \mathrm{C}\end{array}$ & None & $\begin{array}{l}\text { In-situ direct reduction in } \mathrm{H}_{2} \text { at } \\
350^{\circ} \mathrm{C} \text { for } 1 \mathrm{~h}(\mathrm{OR} 350) . \text { Meas- } \\
\text { urements at RT in } \mathrm{H}_{2} \text {. }\end{array}$ & $\begin{array}{l}\text { Smallest clusters with } \sim 10 \AA \text { diameters. PtO CN } 0.5 \pm \\
0.3 \text { with distance } 2.66 \AA \text {. PtPt1 CN } 5.5 \pm 0.3 \text { with } \\
\text { distance } 2.775 \pm 0.003 \AA \text { At PtPt2 CN } 2.0 \pm 0.3 \text { with } \\
\text { distance } 3.96 \pm 0.01 \AA \text {. No Pt-Pt3 or Pt-Pt4 listed. }\end{array}$ & \\
\hline $\begin{array}{l}\text { wt } \% \text { Pt } \\
\text { impregna- } \\
\text { tion from } \\
\text { hexachloro- } \\
\text { plantinic } \\
\text { acid }\end{array}$ & $\begin{array}{c}\gamma-\mathrm{Al}_{2} \mathrm{O}_{3}, \text { Ketjen } \\
\text { CK-300, surface } \\
\text { area } 300 \mathrm{~m}^{2} / \mathrm{g}\end{array}$ & $\begin{array}{l}\text { Dried in air } \\
\text { at } 120^{\circ} \mathrm{C} \\
\text { overnight }\end{array}$ & $\begin{array}{l}\text { Reduced in } \\
\mathrm{H}_{2} \text { at } 300^{\circ} \mathrm{C} \\
\text { for } 4 \mathrm{~h} \text {. }\end{array}$ & $\begin{array}{l}\text { In-situ dried at } 120^{\circ} \mathrm{C} \text { for } 2 \mathrm{~h} \\
\text { and then reduced in } \mathrm{H}_{2} \text { at } \\
300{ }^{\circ} \mathrm{C} \text { for } 1 \mathrm{~h} \text { (LTR). Meas- } \\
\text { urements at }-130^{\circ} \mathrm{C} \text { in } \mathrm{H}_{2} \text {. } \\
\text { In-situ dried at } 120^{\circ} \mathrm{C} \text { for } 2 \mathrm{~h} \\
\text { and then reduced in } \mathrm{H}_{2} \text { at } \\
450{ }^{\circ} \mathrm{C} \text { for } 1 \mathrm{~h}(\mathrm{HTR}) . \text { Meas- } \\
\text { urements at }-130^{\circ} \mathrm{C} \text { in } \mathrm{H}_{2} \text {. }\end{array}$ & $\begin{array}{l}\text { Pt-Pt CN } 4.8 \pm 0.1 \text { with distance of } 2.76 \pm 0.01 \AA \AA \text {. Pt-0 } \\
\text { CN } 1.2 \pm 0.1 \text { with distance of } 2.66 \pm 0.01 \AA . \\
\text { Pt-Pt CN } 3.8 \pm 0.1 \text { with distance of } 2.72 \pm 0.01 \AA . \text { Pt-0 } \\
\text { CN } 1.5 \pm 0.1 \text { with distance of } 2.25 \pm 0.01 \AA .\end{array}$ & [17] \\
\hline $\begin{array}{l}0.35 \text { wt } \% \\
\text { Pt/chloride }\end{array}$ & $\begin{array}{c}\gamma-\mathrm{Al}_{2} \mathrm{O}_{3} \\
\text { surface area } 160 \\
\mathrm{~m}^{2} / \mathrm{g}\end{array}$ & $\begin{array}{l}\text { Calcined in } \\
\text { Dair at } 525^{\circ} \mathrm{C} \text {. }\end{array}$ & $\begin{array}{l}\text { Reduced at I } \\
700^{\circ} \mathrm{C} \text { in } \mathrm{H}_{2}\end{array}$ & $\begin{array}{l}\text { In-situ re-reduction at } 700^{\circ} \mathrm{C} \text { in } \\
\mathrm{H}_{2} \text { for } 30 \mathrm{~min} .\end{array}$ & $\begin{array}{l}\text { Biplanar Pt clusters with diameters of } \sim 0.88 \mathrm{~nm} \text {. PtPt } \\
\text { CN } 3.3 \pm 0.7 \text { with distance of } 2.70 \pm 0.01 . \mathrm{Pt}-\mathrm{C} \mathrm{CN} 1.9 \\
\pm 0.3 \text { with distance of } 2.5 \pm 0.01 \text {. Additional Pt-Pt CNs } \\
\text { for } 2^{\text {nd }}, 3^{\text {rd }} \text {, and } 4^{\text {th }} \text { shells indicating biplanar buckled } \\
\text { morphology. }\end{array}$ & {$[22,23]$} \\
\hline $\begin{array}{l}0.35 \text { wt } \% \\
\text { Pt/chloride }\end{array}$ & $\begin{array}{l}\gamma-\mathrm{Al}_{2} \mathrm{O}_{3} \text { surface } \\
\text { area } 160 \mathrm{~m}^{2} / \mathrm{g}\end{array}$ & $\begin{array}{l}\text { Calcined in } \\
\text { air at } 525^{\circ} \mathrm{C} \text {. }\end{array}$ & None & $\begin{array}{l}\text { As Received. Measurements } \\
\text { at RT in Air. } \\
\text { In-situ reduction at } 250^{\circ} \mathrm{C} \text { in } \mathrm{H}_{2} \\
\text { for } 30 \text { min. Measurements at } \\
\text { RT in } \mathrm{H}_{2} \text {. } \\
\text { In-situ reduction at } 300-350{ }^{\circ} \mathrm{C} \\
\text { in } \mathrm{H}_{2} \text { for } 30 \text { min. Measurements } \\
\text { at RT in } \mathrm{H}_{2} \text {. } \\
\text { In-situ reduction at } 400,500, \\
\text { and } 700^{\circ} \mathrm{C} \text { in } \mathrm{H}_{2} \text { for } 30 \text { min. } \\
\text { Measurements at RT in } \mathrm{H}_{2} .\end{array}$ & 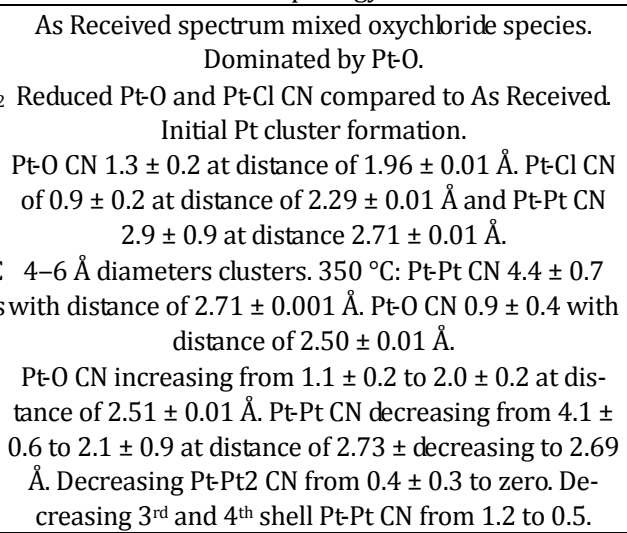 & $\begin{array}{c}\text { This } \\
\text { paper. }\end{array}$ \\
\hline
\end{tabular}

by $\mathrm{H}_{2}$ chemisorption measurements. A follow-up study on the Pt cluster morphology [21] extracted the $1^{\text {st }}, 2^{\text {nd }}$, and $3^{\text {rd }}$ nearest neighboring $\mathrm{Pt}-\mathrm{Pt}$ coordination numbers from the EXAFS spectra. These data suggested mixed Pt particle morphology including biplanar particles for Pt on alumina.

The evolution of Pt cluster formation starting from the oxidized impregnated Pt speciation as it transforms to reduced metal clusters was studied in 1988 by Le Normand et al. [33]. 
The temperature programmed reduction (TPR) spectrum shown in Fig. 1(A) was used to determine the isothermal hold temperature of $180{ }^{\circ} \mathrm{C}$ for the in-situ EXAFS measurements. The $\sim 2 \mathrm{wt} \% \mathrm{Pt}$ and $2 \mathrm{wt} \% \mathrm{Cl}$ on $\gamma-\mathrm{Al}_{2} \mathrm{O}_{3}$ samples were prepared from platinum hexachloride wet impregnation on $\gamma-\mathrm{Al}_{2} \mathrm{O}_{3}$ with surface area of $240 \mathrm{~m}^{2} / \mathrm{g}$. The catalyst was dried for $12 \mathrm{~h}$ in air at $120^{\circ} \mathrm{C}$. The Pt EXAFS spectra from the initial dried and then air exposed catalyst sample were described by an average Pt CN of 2.90 and $4.4 \mathrm{Cl}$ with bond lengths of 2.0 and $2.32 \AA$, respectively. During the isothermal hold but before Pt cluster growth the Pt first shell $\mathrm{O}$ and $\mathrm{Cl} \mathrm{CN}$ decreases from $\sim 6$ to $\sim 4$ with mostly a reduction in the $\mathrm{Cl}$ coordination (Fig. 1(B)). The EXAFS spectra from incipient Pt cluster formation required two unique Pt-Pt distances at 2.70 and $2.80 \AA$ A. The distance of 2.80 $\AA$ was hypothesized to be due to Pt atoms located just above two oxygen atoms of the (111) alumina layer. This was again suggested 12 years later in 1996 by direct imaging of small Pt clusters by Nellist et al. [37] and is discussed in more detail below. During cluster growth, the Pt-Cl coordination decreased slightly while Pt-O coordination remained nearly constant. Overall this trend suggested two-dimensional Pt metal growth such that the average metal to support interaction remained constant regardless of cluster size. Initial clusters formed with the longer Pt-Pt bond length of $2.8 \AA$ were suggested to be unstable, formed by tetrahedral vacancies within the $\gamma-\mathrm{Al}_{2} \mathrm{O}_{3}$ (111) that can also be $2.8 \AA$ apart. When clusters became larger the distances contracted but with larger disorder $[33,36]$.

The effect of drying and/or calcination on the final Pt cluster morphology was demonstrated in 1995 by Muñoz-Páez et al. [34]. This study showed that drying or calcination of the oxidic form of the catalyst before reduction decomposed neutral and mobile oxidized Pt species, which increased the interaction with support leading to a decreased size of Pt clusters [34]. The $1 \mathrm{wt} \% \mathrm{Pt}$ on $\gamma-\mathrm{Al}_{2} \mathrm{O}_{3}$ catalyst samples were prepared by incipient wetness of $\left[\mathrm{Pt}\left(\mathrm{NH}_{3}\right)_{4}\right](\mathrm{OH})_{2}$ on $\gamma-\mathrm{Al}_{2} \mathrm{O}_{3}$ support, Ketjen CK-300 with surface area of $200 \mathrm{~m}^{2} / \mathrm{g}$. Catalyst were dried at $120^{\circ} \mathrm{C}$ for $15 \mathrm{~h}$ to remove physisorbed water and decompose the initial precursor (DEC) to prevent sintering during the sub- sequent treatment in $\mathrm{H}_{2}$ at $350{ }^{\circ} \mathrm{C}$ (DECH350). Comparisons were made to two other catalysts, one calcined at $350{ }^{\circ} \mathrm{C}$ in air, and another without pretreatment prior to reduction, denoted as OR350 and R350, respectively. The Pt EXAFS results for the three catalysts: dried (DECH350), no pre-treatment (R350) and calcined (OR350), each followed by reduction in $\mathrm{H}_{2}$ at $350{ }^{\circ} \mathrm{C}$, are shown in Table 2. In addition to the Pt neighbors listed in Table 2, The EXAFS spectrum from OR350 also includes a Pt-O signal with CN $0.5 \pm 0.3$ and bond length of $2.66 \pm 0.03 \AA$.

In terms of $\mathrm{Pt}$ cluster size, the number of $\mathrm{Pt}$ atoms for spherical particle that would result in the measured EXAFS CN ( $N$ Pt-Pt) is given as $N_{\text {atoms }}$ in Table 2 . The smallest particles were observed for the calcined sample OR350 with $N_{\text {atoms }}$ of 14-19. The next smallest particles are for the dehydrated sample DECH350 with $N$ atoms of 40 . The largest particles were found after direct reduction with $N_{\text {atoms }}$ for the $1^{\text {st }}$ shell of 650 . The directly reduced sample showed smaller than expected coordination number (CN) for the $2^{\text {nd }}$ shell of 360 rather than 650 as observed for the $1^{\text {st }}$ and $3^{\text {rd }}$ shells as expected for spherical particles. The reason for the abnormally small $2^{\text {nd }}$ shell $\mathrm{CN}$ was not recognized at the time, but can now be explained by the largest particles having biplanar morphology. Hence, calcination prior to reduction led to the smallest clusters, while drying gave spherical clusters of medium size and direct reduction resulted in the largest Pt clusters with biplanar morphology.

In addition to changing the initial oxidized Pt speciation, cluster morphology and Pt cluster size were affected by pretreatment due to changes in hydroxylation of the support. In the example above, the Pt particle size increases with hydroxylation of a support in the order of calcination, drying, and direct reduction. A complementary DFT investigation of 13 atom clusters of $\mathrm{Pd}$ and $\mathrm{Pt}$ on $\gamma-\mathrm{Al}_{2} \mathrm{O}_{3}$ also highlighted the importance of hydrogen both in hydroxylation of the support and on metal cluster chemistry [38]. Hydroxylation of the support weakened the metal support interaction causing three dimensional clusters to be more stable while dehydroxylated support caused biplanar clusters. In this DFT study the optimized structure for $13 \mathrm{Pt}$ atoms on a dehydrated (100) surface appeared to have
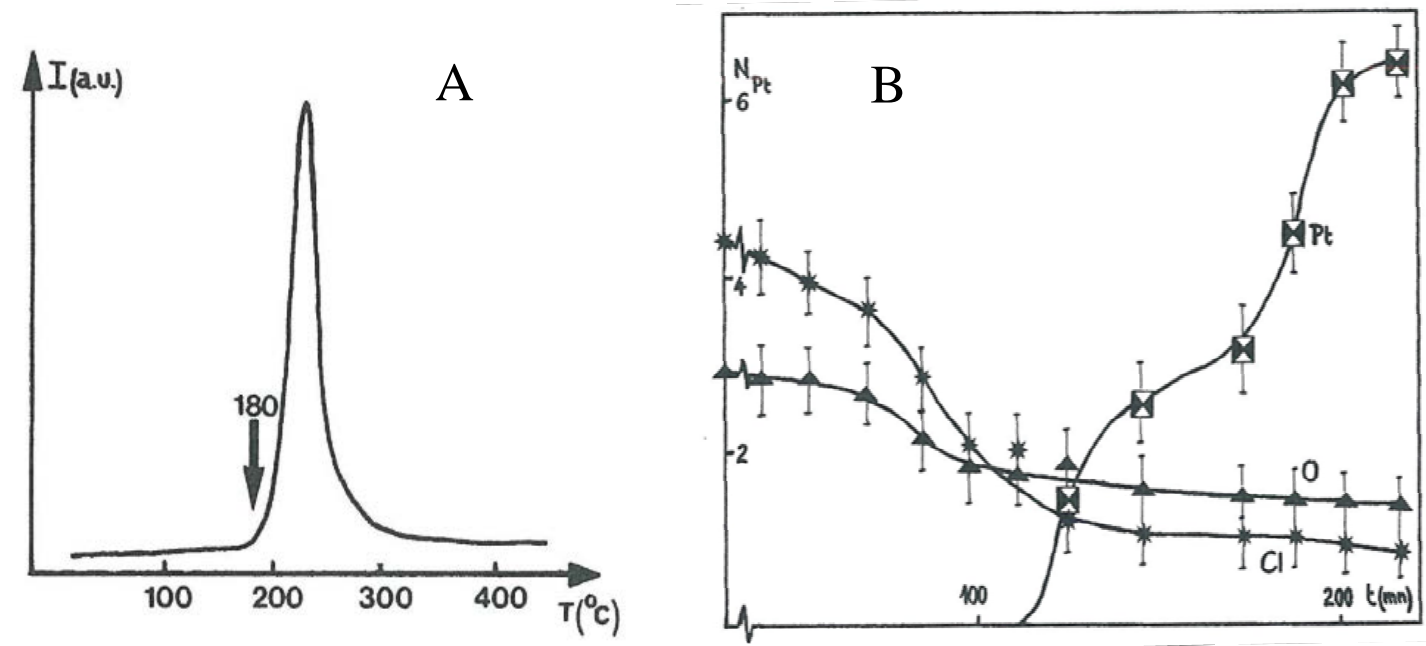

Fig. 1. TPR spectrum of Pt/ $\mathrm{Al}_{2} \mathrm{O}_{3}$ catalyst showing onset of reduction at $180{ }^{\circ} \mathrm{C}(\mathrm{A})$. EXAFS CN for Pt-O, Pt-Cl, and Pt-Pt as a function of time during isothermal hold at $180^{\circ} \mathrm{C}$ (B). Reprinted with permission from [30] Copyright 1988 The Chemical Institute of Canada. 
Table 2

EXAFS results for coordination numbers, calculated number of atoms per particle, and calculated particle diameter for reduced samples. Reprinted with permission from [34] Copyright 1995 American Chemical Society.

\begin{tabular}{|c|c|c|c|c|c|c|c|c|c|}
\hline \multirow[b]{2}{*}{ Shell } & \multicolumn{3}{|c|}{ DECH350 } & \multicolumn{3}{|c|}{ R350 } & \multicolumn{3}{|c|}{ OR350 } \\
\hline & PtPt CN & $N_{\text {atoms }}$ & $\mathrm{D}(\AA)$ & PtPt CN & $N_{\text {atoms }}$ & $\mathrm{D}(\AA)$ & Pt-Pt CN & $N_{\text {atoms }}$ & $\mathrm{D}(\AA)$ \\
\hline 1 & 7.2 & 40 & 13 & 10.1 & 650 & 35 & 5.5 & 14 & 9 \\
\hline 2 & 2.8 & 40 & 13 & 4.4 & 360 & 27 & 2.9 & 19 & 11 \\
\hline 3 & 8.3 & 40 & 13 & 17.5 & 650 & 35 & & & \\
\hline
\end{tabular}

seven Pt atoms in contact with the support. Similarly, for the much larger particles measured by Muñoz-Páez, the $2^{\text {nd }}$ shell $\mathrm{Pt}-\mathrm{Pt} \mathrm{CN}$ was reduced compared to the $1^{\text {st }}$ and $3^{\text {rd }}$ shell Pt-Pt CN which is consistent with biplanar morphology. The cluster morphology for the more hydroxylated case of R350 was approximately 4 layers thick suggesting one quarter of the atoms in contact with the support, which was consistent with the values measured by Muñoz-Páez. The study highlighted the distorted Pt geometries that were stabilized on the support only through the strong interactions with the $\gamma-\mathrm{Al}_{2} \mathrm{O}_{3}$ surface, exposing highly undercoordinated $\mathrm{Pt}$ atoms that were expected to be key players in catalyzing reactions $[25,38]$.

A direct imaging study [37] of small Pt clusters (of 3 or more atoms) on $\gamma-\mathrm{Al}_{2} \mathrm{O}_{3}$ showed the cluster configuration was constrained to match the surface structure of $\gamma-\mathrm{Al}_{2} \mathrm{O}_{3}$. This sample was prepared to have $3 \mathrm{wt} \% \mathrm{Pt}$ on $\gamma-\mathrm{Al}_{2} \mathrm{O}_{3}$. Pt trimers were observed as isosceles triangles which occur on the $\gamma-\mathrm{Al}_{2} \mathrm{O}_{3}$ (110) surface, rather than close-packed equilateral triangle of metallic Pt (Fig. 2). The Pt-Pt bond length matched the shortest 0-0 distance on the alumina surface of $2.8 \AA$, as previously observed for incipient Pt-Pt cluster formation $[33,39]$. The surface Pt maybe doubly coordinated by oxygen with Pt-O distance of $2.68 \AA$, as previously observed in several EXAFS studies $[22,34,40]$. It was also suggested that Pt could displace surface Al resulting in a short Pt-O bond of $2.28 \AA$.

A study by Vaarkamp et al. [17] demonstrated that the reduction temperature for $1 \mathrm{wt} \% \mathrm{Pt}$ on $\gamma-\mathrm{Al}_{2} \mathrm{O}_{3}$ also affected the cluster morphology. Catalysts were prepared by impregnation
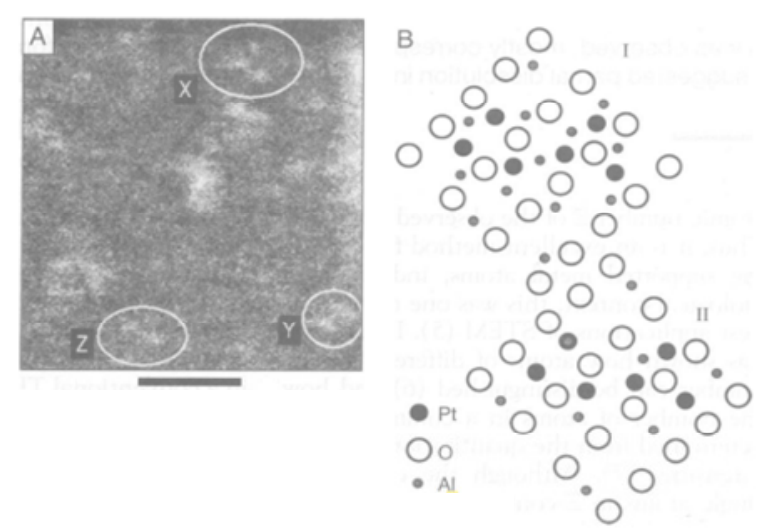

Fig. 2. STEM image of Pt clusters on $\gamma-\mathrm{Al}_{2} \mathrm{O}_{3}$ (A). Schematic of the alumina surface with Pt trimer formation showing isosceles triangle shape (B). Reprinted with permission from [31] Copyright 1996 The American Association for the Advancement of Science. of Ketjen CK-300 (200 m²/g) with aqueous solution of hexachloroplatinic acid $\left(\mathrm{H}_{2} \mathrm{PtCl}_{6}\right)$, dried at $120{ }^{\circ} \mathrm{C}$ overnight, and then reduced at $300{ }^{\circ} \mathrm{C}$ for $4 \mathrm{~h}$. Prior to the EXAFS measurements the catalyst was treated in-situ by drying at $120^{\circ} \mathrm{C}$ for 2 $\mathrm{h}$, and then reduced at 300 or $450{ }^{\circ} \mathrm{C}$. The final measurements were made at $-130{ }^{\circ} \mathrm{C}$ in $\mathrm{H}_{2}$ to increase the signal to noise ratio in the measured EXAFS spectra. They showed an increased interaction of the alumina with $\mathrm{Pt}$ and how this interaction dominated at high reduction temperatures causing further flattening and shrinking of the EXAFS coherent Pt cluster. The Pt cluster size measured from the Pt-Pt CN in EXAFS spectra collected after reduction showed a decrease in the Pt-Pt CN after high $\left(450{ }^{\circ} \mathrm{C}\right)$ temperature $(\mathrm{HT})$ compared to low $\left(300^{\circ} \mathrm{C}\right)$ temperature (LT) reduction. The decrease in Pt-Pt CN after HT reduction from $4.8 \pm 0.1$ to $3.8 \pm 0.1$ was explained by a further flattening of the Pt clusters. The contraction of the Pt- $\mathrm{O}$ bond length from $2.66 \AA$ after LT reduction to $2.25 \AA$ after HT reduction was explained by the desorption of $\mathrm{H}_{2}$. DFT studies suggested that very limited hydrogen can adsorb/desorb between the Pt clusters and the alumina support, and only for partially hydroxylated $\left(\begin{array}{lll}1 & 1 & 0\end{array}\right)$ surface. Furthermore, the changes to bond distances due to this loss/gain of $\mathrm{H}$ results in only minor $(0.1 \AA)$ changes in bond distances [38]. It was suggested that the longer Pt-0 bond of $2.66 \AA$ observed after LTR may indeed be evidence for Pt--Al signal $[25,38]$. STEM imaging and DFT studies indicated $\mathrm{Pt}$ incorporation into $\mathrm{Al}^{3+}$ vacancies might account for the short $2.25 \AA$ Pt-O bond for biplanar morphology as observed by Vaarkamp et al. $[25,37,38]$ after HT reduction showing evidence of the increased support interaction affecting the Pt particle morphology. The short $2.25 \AA$ Pt-O bond was not observed for more three dimensional clusters with higher hydrogen coverage [38] helping to rationalize the absence of this signal after LT reduction. The longer Pt-O bond observed after LT reduction at $2.66 \AA$ is not as easily rationalized. It could be a signal from neighboring $\mathrm{Al}$ atoms in the support as suggested [38], but the disappearance after HT reduction would not be expected; instead the signal would be expected to become even stronger. Pt biplanar morphologies have repeatedly shown small but consistent Pt--Al signal in several DFT studies $[24,25,38]$. An alternative suggestion may be another location on the alumina support perhaps with reconstruction of the surface and/or a different Pt morphology more consistent with that observed by Nellist et al. [37]. Sample measurement conditions are of the upmost importance, and these measurements were uniquely made at $-130{ }^{\circ} \mathrm{C}$ in hydrogen gas.

A study by the current authors of $0.35 \mathrm{wt} \% \mathrm{Pt}$ on alumina after reduction to high temperature $\left(700^{\circ} \mathrm{C}\right)$ in $\mathrm{H}_{2}$ by aberra- 
tion-corrected transmission electron microcopy (AC-TEM), in conjunction with EXAFS and AC-STEM, showed a narrow Pt size distribution of $0.88 \mathrm{~nm}$ with biplanar morphology [22,23]. This study used a unique STEM method of redistribution of Pt atoms with high electron dosage to accurately determine the number of Pt atoms within a cluster. The number of atoms in the cluster was compared to the area of the original Pt cluster to determine the number of Pt layers in the particle. The results showed that the Pt cluster contained 1-2 layers in a biplanar morphology. The AC-TEM images showed registry of the Pt clusters on the alumina support forming a buckled morphology that was consistent with EXAFS results.

Briefly, this review shows that the Pt morphology on $\gamma-\mathrm{Al}_{2} \mathrm{O}_{3}$ is complex. The initial oxidized speciation, whether it is hydrated or dehydrated, and the hydroxylation of the support has a dramatic effect on the Pt mobility and hence the final Pt cluster size and morphology. The reduction temperature further modifies the Pt morphology and perhaps the cluster size.

\subsection{Formation and Reduction of Pt Clusters}

The following presents an in-depth analysis of our $0.35 \mathrm{wt} \%$ Pt on alumina catalyst [22], bringing together additional analysis and insights from the review above. The authors [22] combine state-of-the-art AC-STEM and EXAFS techniques to study the $0.35 \mathrm{wt} \% \mathrm{Pt}$ catalyst through the reduction process at temperature steps up to $700{ }^{\circ} \mathrm{C}$. The catalyst was prepared via impregnation of platinum-chloride precursor, followed by calcination at $525{ }^{\circ} \mathrm{C}$ in air prior to reduction. EXAFS measurements were made in-situ at both the $\mathrm{Pt}$ L3-edge and the $\mathrm{Cl}$ K-edge during TPR and at the $\mathrm{Pt}_{3}$-edge at room temperature in $\mathrm{H}_{2}$ after a 30 min hold at the reduction temperature noted.

The Pt L3-edge X-ray absorption near edge structure (XANES) spectra of the oxidized catalyst show the typical strong absorption white-line at the absorption edge due to empty $5 d$ electron orbitals of $\mathrm{Pt}^{4+}$. As the $\mathrm{Pt}$ is reduced, these orbitals are filled and the white line height intensity is thus reduced (Fig. 3(A)). The white-line height is plotted with the TPR spectra in Fig. 3(B). The large stars in Fig 3(B) indicate the temperatures studied by STEM and EXAFS. These data show that the Pt is reduced between 200 and $350{ }^{\circ} \mathrm{C}$ and at a similar temperature as the maximum uptake of $\mathrm{H}_{2}$ consumption in the TPR experiment, suggesting that much of the $\mathrm{H}_{2}$ consumption is for Pt reduction.

The Cl K-edge XANES has a unique pre-edge peak due to binding with metal such as Pt with available $4 d$ electrons. The pre-edge peak is caused by the opening of unfilled electron orbitals with $\mathrm{d}$ character caused by the hybridization of the $\mathrm{Pt}$ $4 d$ with the $\mathrm{Cl} 3 \mathrm{p}$ electrons. The pre-edge peak height is proportional to the amount of $\mathrm{Cl}-\mathrm{Pt}$ bonding. Fig. 4(A) shows the $\mathrm{Cl}$ K-edge XANES for the catalyst sample during TPR in $\mathrm{H}_{2}$. The inset shows an enlarged view of the pre-edge peak. The height of the $\mathrm{Cl}$ pre-edge peak is plotted as a function of temperature in Fig. 4(B). The fastest rate of Cl-Pt ligand loss occurs between 200 and $350{ }^{\circ} \mathrm{C}$, similar to the Pt white-line height reduction, suggesting that $\mathrm{Cl}$ ligand loss occurs at similar temperatures to $\mathrm{O}$ ligand loss. The reduction of oxy-chlorinated Pt species is expected to occur more quickly than purely oxidized species [41]. The as received $\mathrm{Pt} / \gamma-\mathrm{Al}_{2} \mathrm{O}_{3}$ catalyst before reduction contains a mixture of both oxy-chlorinated Pt and purely oxidized Pt species, such that this trend is not observable based on the Pt and $\mathrm{Cl}$ XANES alone.

The EXAFS/XANES spectra show large changes during the initial reduction process as shown in the comparison of as received, 250, 300, and $350{ }^{\circ} \mathrm{C}$ spectra (Fig. 5(A)). The bar chart in Fig. 5(B) shows the EXAFS CN and bond lengths for these spectra. Initially the Pt in the oxidized catalyst is coordinated to $\mathrm{O}$ and $\mathrm{Cl}$ in a ratio of 2 to 1 . As observed previously, the number of O-ligands drops more quickly than the Cl-ligands during the initial reduction process but persists at higher reduction temperatures. The initial Pt-O bond length of $2.0 \AA$ is consistent with oxidized Pt compounds such as $\mathrm{PtO}_{2}$. Similarly, STEM images from the initial oxidized catalyst show only isolated Pt atoms (Fig. 5(C)).
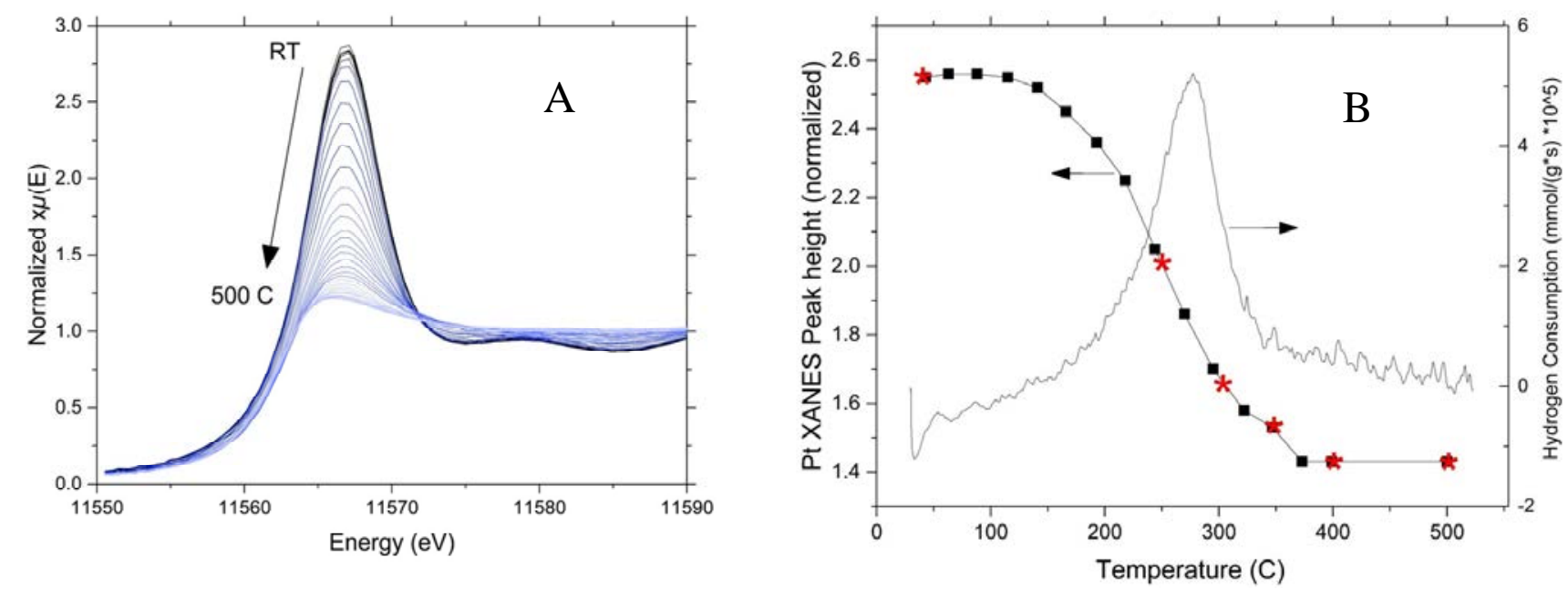

Fig. 3. Pt $\mathrm{L}_{3}$-edge XANES during TPR from RT to $500^{\circ} \mathrm{C}$ (A). Pt white line height as a function of temperature during TPR overlaid with $\mathrm{H}_{2}$ consumption (B). 

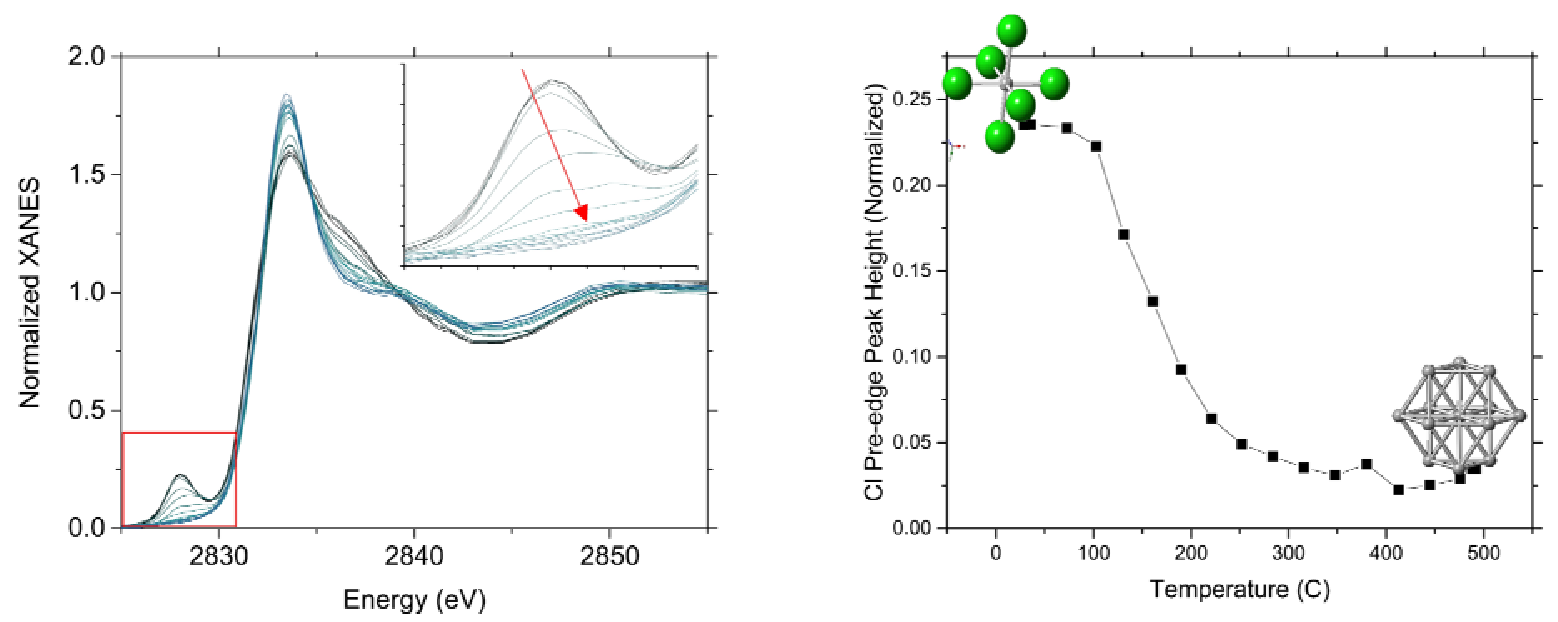

Fig. 4. $\mathrm{Cl} \mathrm{K}$-edge XANES during TPR from $\mathrm{RT}$ to $500^{\circ} \mathrm{C}$ with inset showing pre-edge peak (A). Cl pre-edge peak height as a function of temperature (B).
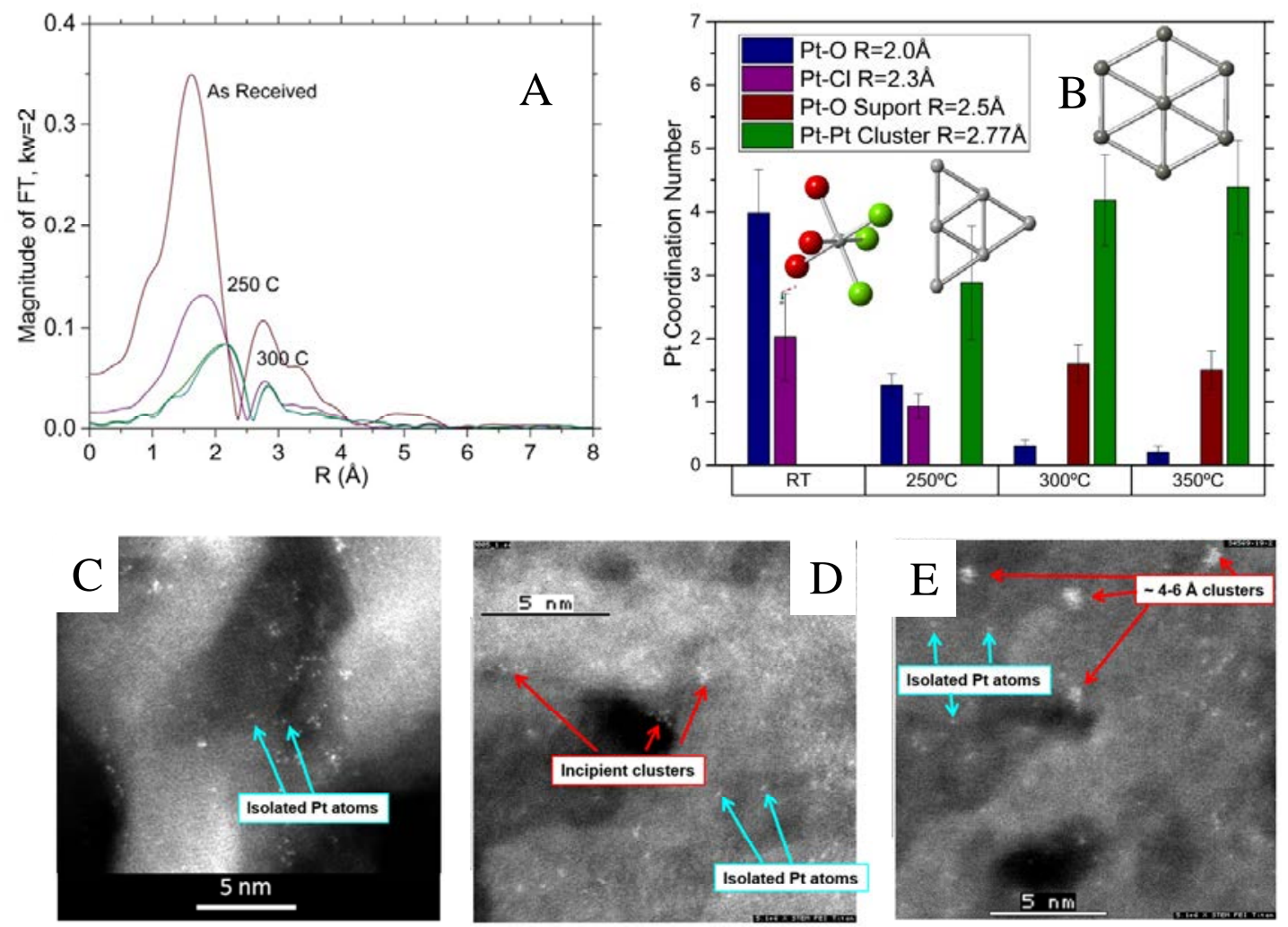

Fig. 5. Pt on $\gamma-\mathrm{Al}_{2} \mathrm{O}_{3}$ after low temperature reduction from as received (AR) to $350{ }^{\circ} \mathrm{C}$. Magnitude of the Fourier transform EXAFS spectra (A) and EXAFS results for coordination numbers and representative models (B). AC-STEM images as received (C) and after $250^{\circ} \mathrm{C}$ reduction (D) and after 350 ${ }^{\circ} \mathrm{C}$ reduction (E).

\subsection{1. $250^{\circ} \mathrm{C}$ reduction}

The Pt EXAFS spectrum from the Pt on $\gamma-\mathrm{Al}_{2} \mathrm{O}_{3}$ catalyst after reduction at $250{ }^{\circ} \mathrm{C}$ shows the initial formation of Pt clusters with significant decrease in the oxidic-ligand neighbors (both $\mathrm{O}$ and $\mathrm{Cl}$ ). The Pt-O CN drops by $70 \%$ from 4 to $1.3 \pm 0.2$ while the $\mathrm{Pt}-\mathrm{Cl} \mathrm{CN}$ drops by $50 \%$ from 2 to $0.9 \pm 0.2$. The first nearest neighbor Pt-Pt CN is $2.9 \pm 0.9$ indicating that on the average each Pt atom is coordinated by three other Pt to make a 4-6 Pt atom cluster (Fig. 5(B) insert). STEM images confirm many isolated atoms and a few 4-6 atom clusters (Fig. 5(D)), in good agreement with the EXAFS results. The EXAFS spectra include a longer Pt--Pt signal with distance of 3.19 Å which corresponds to a few $\mathrm{PtO}_{2}$ like clusters on the support. The initial first nearest neighbor Pt-Pt bond length of $2.71 \pm 0.01 \AA$ is typical for contracted small Pt clusters as compared to the bulk metallic Pt-Pt bond length of $2.77 \AA$ A. No elongated Pt-Pt bond length of $2.8 \AA$ is observed in the low temperature reduction spectra [33] 

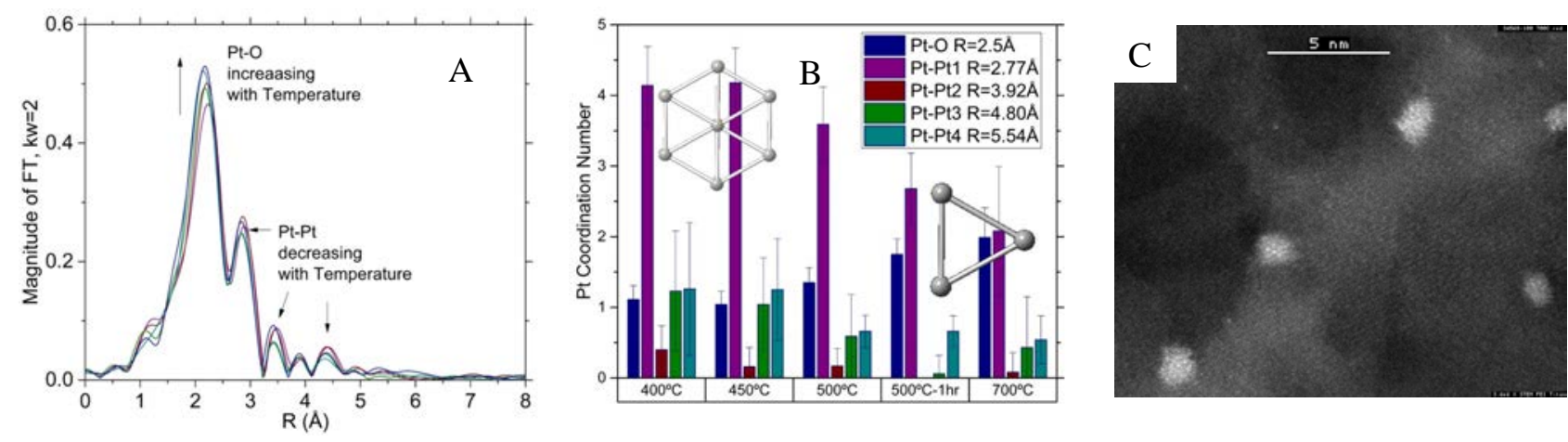

Fig. 6. Pt on $\gamma-\mathrm{Al}_{2} \mathrm{O}_{3}$ after high temperature reduction from as $400{ }^{\circ} \mathrm{C}$ to $700{ }^{\circ} \mathrm{C}$. Magnitude of the Fourier transform EXAFS spectra at room temperature (A) and EXAFS results for coordination numbers and representative models (B). AC-STEM image after $700{ }^{\circ} \mathrm{C}$ reduction (C).

, which suggests that this unique Pt speciation may occur at even lower reduction temperatures.

\subsubsection{0 and $350^{\circ} \mathrm{C}$ reduction}

EXAFS results for the Pt on $\gamma-\mathrm{Al}_{2} \mathrm{O}_{3}$ catalyst sample after reduction at 300 and $350{ }^{\circ} \mathrm{C}$ show a more simplified Pt coordination environment. There is a residual Pt-0 signal at the $2.0 \AA$ distance and a longer Pt-O at $2.50 \pm 0.01 \AA$. The $\mathrm{Cl}$ ligand signal is no longer detected. The Pt-O bond at $2.50 \pm 0.01 \AA$ is likely a support interaction bond distance, although the bond length is slightly longer than the DFT prediction of 2.1 to $2.4 \AA[25,38]$. The Pt-Pt CN continues to grow to its largest values of $4.2 \pm 0.7$ and $4.4 \pm 0.7 \AA$ for 300 and $350{ }^{\circ} \mathrm{C}$ spectra, respectively. These Pt-Pt coordination numbers are consistent with 4-6 Å diameter Pt clusters consisting of $7 \mathrm{Pt}$ atoms as shown in Fig. 5(B). AC-STEM images (Fig. 5(E)) agree with identification of many 4-6 Å clusters.

\subsubsection{Pt coordination numbers after high temperature reduction}

After higher reduction temperatures of 400, 500, and 700 ${ }^{\circ} \mathrm{C}$, the Pt EXAFS spectra (Fig. 6(A)) show an increase in the $\mathrm{Pt}-\mathrm{O}$ support signal and a decrease in the Pt-Pt cluster signal. These data suggest the clusters become tightly coordinated to the support and loose coherence in the Pt-Pt bond distance. The EXAFS modeling results show an increase in the Pt-O CN from $1.1 \pm 0.2 \AA$, to $1.4 \pm 0.2 \AA$, and finally $2.0 \pm 0.2 \AA$ for the reduction temperatures of 400,500 , and $700{ }^{\circ} \mathrm{C}$ respectively. At the final reduction temperature of $700{ }^{\circ} \mathrm{C}$, the average $\mathrm{Pt}-\mathrm{O} \mathrm{CN}$ of two suggests each Pt coordinated to two $\mathrm{O}$ from the support [37]. The $2^{\text {nd }}$ nearest neighboring Pt CN decreases with increasing reduction temperature from $0.4 \pm 0.3$ to $0.2 \pm 0.3$ to finally $0.1 \pm 0.3$ for 400,500 , and $700{ }^{\circ} \mathrm{C}$. The lack of a $2^{\text {nd }}$ neighbor coordination distance is strong evidence for biplanar Pt particle morphology, for which this signal is absent. The $1^{\text {st }}$ nearest neighboring Pt $\mathrm{CN}$ decreases steadily with increased reduction temperature and becomes about 2 after $700{ }^{\circ} \mathrm{C}$ reduction, which is similar to the number of oxygen ligands to the support. The $3^{\text {rd }}$ and $4^{\text {th }}$ shell coordination numbers are very small and do not grow with reduction temperature.

The biplanar nature of the HT reduced Pt clusters is further confirmed by detailed AC-STEM analysis. High angle annular dark field (HAADF) intensity of the clusters are integrated to calculate the thickness of the clusters using single atoms within the same image as reference intensity (Fig. 7). Based on this method, the clusters of the $500{ }^{\circ} \mathrm{C}$ reduction clusters were found to be 2-3 layers thick confirming biplanar morphology (Fig. 7(B)).

\subsubsection{0 and $700{ }^{\circ} \mathrm{C}$ high temperature reduction, STEM and Buckling}

The EXAFS results after reduction at 500 to $700{ }^{\circ} \mathrm{C}$ are consistent with small 3 atom Pt trimers $(\mathrm{CN}=2)$ as shown in Fig. 6(B). In stark contrast, AC STEM images after $700{ }^{\circ} \mathrm{C}$ reduction show large $9 \AA$ A clusters containing 15-20 atoms (Fig. 6(C)). The EXAFS CN for such a cluster is calculated be to approximately 5 , instead of the measured value of 2 , which is simply too large a difference to be considered within experimental error. In this high temperature reduction regime AC STEM and EXAFS disagree profoundly on the average Pt cluster size.

Some insight into this apparent contradiction comes from our previous study using state-of-the-art Argonne chromatic aberration-corrected (ACAT) TEM of a similar $0.35 \mathrm{wt} \% \mathrm{Pt}$ on chlorided $\gamma-\mathrm{Al}_{2} \mathrm{O}_{3}$ sample after quick reduction to $700{ }^{\circ} \mathrm{C}$. ACAT-TEM allows individual Pt atoms on the alumina support to be imaged and demonstrates that the Pt atoms are in tight registry with the alumina support [22]. Fig. 8 shows one individual Pt cluster made up of atoms (black) marked with green and pink dots and a schematic of the buckled cluster as an inset (Fig. 8). Detailed EXAFS modeling is consistent with this buckled morphology and an average coordination of each Pt atoms

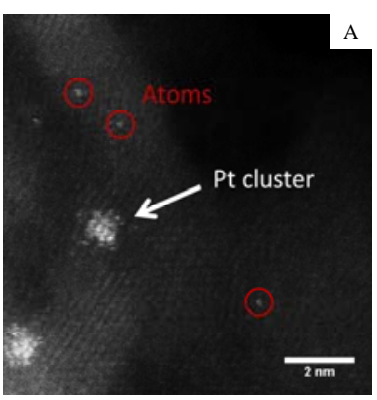

B

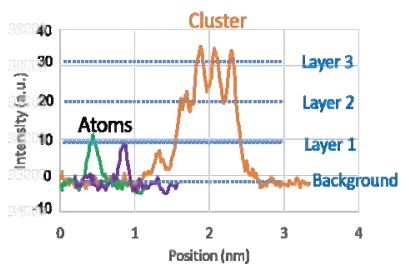

Fig. 7. Pt on $\mathrm{\gamma}-\mathrm{Al}_{2} \mathrm{O}_{3}$ after high temperature reduction $500{ }^{\circ} \mathrm{C}$ reduction. AC-STEM image after $500{ }^{\circ} \mathrm{C}$ reduction (A). High angle annular dark field (HAADF) intensity of the clusters (B). 
by 2 support oxygen[22]. Hence at high reduction temperatures the strong support interaction results in large distortions of the Pt cluster, and an apparent reduction in the $1^{\text {st }}$ neighbor coordination measured by EXAFS.

From this study, we suggest that both EXAFS and STEM imaging are indeed of the same clusters but that the alumina support is distorted such that each 15 atom Pt cluster observed in AC STEM is made up of many Pt trimers as observed by EXAFS. A simplified depiction is shown in Fig. 9 for two different 10-11 atom Pt clusters. Fig. 9(A) shows coherent structure with an average Pt-Pt CN of 3.8 while Fig. 9(B) shows a distorted cluster made up of $5 \mathrm{Pt}$ trimers with an average Pt-Pt CN of 2.2. STEM imaging will give the same cluster size for both configurations, while EXAFS CN differs. It is our hypothesis that after slow reduction at high temperatures the EXAFS Pt-Pt CN decreases while the support oxygen $\mathrm{CN}$ increases due to the distortions imposed by the support and at the same time AC-STEM observes cluster growth. Additional evidence for larger (than trimer) Pt particles comes from the EXAFS results for the $3^{\text {rd }}$ and $4^{\text {th }}$ Pt-Pt shell signals. Isolated trimers would have no signal for the $3^{\text {rd }}$ and $4^{\text {th }}$ shells. Hence the trimers are in close association with each other such that some of the $3^{\text {rd }}$ and $4^{\text {th }}$ shell signals are preserved.

\subsection{Discussion on Pt coordination environment}

Pt and Cl XANES spectra during in-situ reduction give a direct measure of the electronic configuration of $\mathrm{Pt}$ and $\mathrm{Cl}$ as the Pt oxidation state is decreased and the chloride ligands are lost. These data show Pt reduction and $\mathrm{Cl}$ ligand loss occur between 200 and $350{ }^{\circ} \mathrm{C}$, at the same temperatures as the uptake in $\mathrm{H}_{2}$ similar to previous reports [33].

The oxidized state of our catalyst prototype is dominated by oxygen with an average of 4 oxygen ligands and 2 chlorine ligands likely caused by the high temperature $525^{\circ} \mathrm{C}$ calcination.

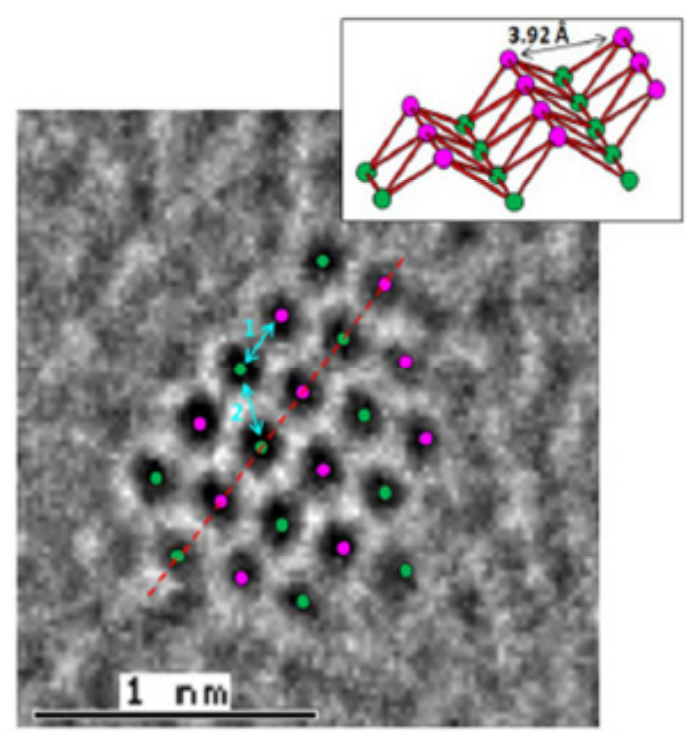

Fig. 8. ACAT TEM image of an individual Pt cluster after $700{ }^{\circ} \mathrm{C}$ reduction. Each Pt atom is registered to alumina plane, with the green atoms below the pink atoms. Reprinted with permission from [21] Copyright 2015 John Wiley and Sons.
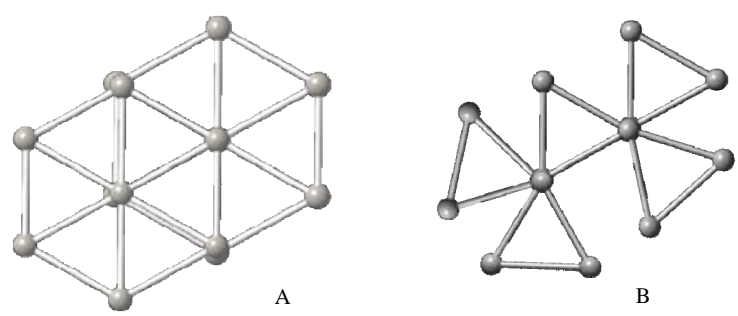

Fig. 9. Configuration of coherent Pt 10 atom cluster (A) and similar distorted Pt 11 cluster made up of 5 Pt trimers (B). STEM imaging will give the same cluster size for both configurations, while EXAFS CN differs being 3.8 for the coherent cluster (A) and 2.2 for the distorted cluster (B).

This is consistent with STEM images showing the dominance of isolated Pt atoms with only a few dimers (Fig. 5(C)). In contrast, in the work by Le Normand et al.[33], the oxidized form of the catalyst after $12 \mathrm{~h}$ calcination at $120^{\circ} \mathrm{C}$ was dominated by chlorine with an average of $4 \mathrm{Cl}$ ligands and 20 ligands. Clearly the lower temperature treatment for $12 \mathrm{~h}$ at $120{ }^{\circ} \mathrm{C}$ preserves more of the original $\mathrm{Cl}$ ligands than the high temperature calcination at $525{ }^{\circ} \mathrm{C}$ [20]. A comparison of the TPR data shows a difference in the Pt reduction temperature, the maximum $\mathrm{H}_{2}$ uptake being approximately $225^{\circ} \mathrm{C}$ after low temperature calcination while high temperature calcination results in a higher reduction temperature of $300{ }^{\circ} \mathrm{C}$. It is thus speculated that preservation of more $\mathrm{Cl}$ ligands at a lower calcination temperature leads to less Pt interaction with the support, which then induces a lower reduction temperature. This is consistent with the reduction-oxidation study showing that oxy-chlorinated $\mathrm{Pt}$ species are more readily reduced compared to oxidized Pt species [41].

The formation of 4-6 Pt atom clusters occurs at $250{ }^{\circ} \mathrm{C}$ as observed by STEM, in agreement with EXAFS Pt-Pt CN. The onset of catalytic reforming operating temperature range is $300{ }^{\circ} \mathrm{C}$. Pt reduction at 300 and $350{ }^{\circ} \mathrm{C}$ show cluster growth to an average of $7 \mathrm{Pt}$ atoms as the remaining oxidized ligands are removed. This is the largest EXAFS Pt-Pt coordination number observed under these conditions. Previous studies have observed larger coordination numbers, usually in samples with either or both higher Pt loadings and/or with less Pt-support interaction through lower calcination temperature [33,34], no calcination [34] or very fast reduction [22]. In Muñoz-Páez's study [34], the catalyst with $1 \mathrm{wt} \% \mathrm{Pt}$ was prepared from tetraammineplatinum(II) nitrate, calcined and then reduced at $350{ }^{\circ} \mathrm{C}$. This sample (OR350) exhibited similar $1^{\text {st }}$ shell Pt-Pt coordination number of 5.5 compared to our $0.35 \mathrm{wt} \% \mathrm{Pt}$ from chloride precursor calcined at higher temperature of $525{ }^{\circ} \mathrm{C}$ and then reduced at the same temperature of $350{ }^{\circ} \mathrm{C}$. The largest difference is in the second shell coordination number. The amine precursor with lower calcination temperature and 3 times higher Pt weight loading resulted in more spherical particles with second shell Pt-Pt CN of 2.0. No second shell Pt-Pt signal was observed for the chloride precursor with higher calcination temperature and 3 times less Pt weight loading. These differences are likely important factors for the difference in Pt morphology. 
In the study by Vaarkamp et al. [17], the average Pt coordination environment of the sample after $300{ }^{\circ} \mathrm{C}$ reduction of 1 wt $\%$ Pt from hexachloroplaninic acid dried at $120^{\circ} \mathrm{C}$ overnight was found to include Pt-Pt CN of $4.8 \pm 0.1$ and Pt-O CN of $1.2 \pm$ 0.1 with bond distances of 2.76 and $2.66 \AA$, respectively. This average Pt coordination is surprisingly similar to our $0.35 \mathrm{wt} \%$ Pt from chloride precursor calcined at $525^{\circ} \mathrm{C}$ and then reduced at $300{ }^{\circ} \mathrm{C}$ for which they are $4.2 \pm 0.7 \mathrm{Pt}-\mathrm{Pt}$ and $1.3 \pm 0.4 \mathrm{Pt}-\mathrm{O}$. From DFT study, the longer Pt-O bond length of $2.66 \AA$ A cannot be due to interaction between Pt and the support oxygen which was found to be in the distance ranging from 2.1 to $2.4 \AA$, but rather may be from $\mathrm{Al}$ of the support with distance of 2.61 to $2.64 \AA$ A. The Pt-O signal observed in our data is at a somewhat shorter distance than found by Vaarkamp et al. [17] at $2.50 \AA$. This is just outside the rather broad range predicted by DFT which extends to $2.4 \AA$ [25,38].

Once the Pt-0 signal from the support at $2.5 \AA$ is established the clusters no longer grow as the reduction temperature increases to 400,500 , and finally $700{ }^{\circ} \mathrm{C}$. Instead the EXAFS Pt-Pt $1^{\text {st }}$ shell $\mathrm{CN}$ decreases to 2 as the Pt- $\mathrm{CN}$ increases to 2 at the final reduction temperature of $700{ }^{\circ} \mathrm{C}$. Each $\mathrm{Pt}$ atom on the alumina support is doubly coordinated by oxygen as proposed by Nellist and Pennycook [37], but with Pt-O bond distance slightly shorter than the proposed $2.68 \AA$. The clusters are dominated by a biplanar morphology with limited $2^{\text {nd }}$ nearest neighbors. Even the third and fourth Pt neighbors decrease at the highest reduction temperature, suggesting that the particle decreases in extent as well as in stacking.

In the study by Vaarkamp et al. [17], $300{ }^{\circ} \mathrm{C}$ reduction results in a Pt-Pt bond length nearly equal to that of bulk Pt at $2.76 \AA$ (bulk value is $2.77 \AA$ ). Our data shows much smaller bond distance at $2.71 \AA$, typical for small clusters. This suggests that the clusters are larger or the bond length is stretched due to $\mathrm{H}_{2}$ [24], or possibly pulled by vacancies on the alumina support [42]. After higher temperature reduction at $450{ }^{\circ} \mathrm{C}$ the reported bond length contracts to more typical value of $2.72 \AA$ with Pt-Pt1 CN of 3.8. Our data at $400{ }^{\circ} \mathrm{C}$ reduction shows similar Pt-Pt CN of $4.1 \pm 0.6$ and bond length of $2.72 \AA$. But again, we found Pt-O bond length of $2.5 \AA$ that is likely from the support while Vaarkamp et al. reports much smaller Pt-0 signal at 2.25 $\AA$ Ahich is again more consistent with vacancies on the alumina support. This suggests there is something fundamentally different about the interaction of the support with the Pt clusters of Vaarkamp et al. compared to our clusters. As mentioned before DFT studies suggest Pt-O bond lengths of 2.1 to $2.4 \AA$ can be from the support such that it is possible that this high temperature reported value of $2.25 \AA$ is from support oxygen. Another difference is that the hold time of the reduction temperature was $4 \mathrm{~h}$ in Vaarkamp's study while $30 \mathrm{~min}$. in ours. Finally, Vaarkamp's samples were measured at low temperature, which may have also affected the Pt cluster support interaction.

STEM results normally correlate well with EXAFS but significant discrepancy is observed at the highest reduction temperature of at $700{ }^{\circ} \mathrm{C}$ as shown in Fig. 6. Sample preparation for STEM involves dispersion of a small amount of sample in ethanol with air exposure, which likely causes Pt reoxidation and a change in the Pt-cluster support interaction. It is unlikely that this sample preparation would change the observed Pt cluster size. The Pt particles become tightly registered to the Pt support as observed by Nellist et al. [37], consistent with our EXAFS results of 2 support oxygen coordinated to each Pt atom. This is only possible if most Pt clusters are of a single layer and in tight registration with the alumina. As observed for a similar but different reduction condition, the Pt atoms can become buckled following the uneven topology of the underlying alumina. The only way to reconcile the AC-STEM images of 15-20 atom Pt clusters and the EXAFS results for 3 atom Pt clusters is to build the 15 atom clusters together in a way that distorts the Pt-Pt bonds significantly such that the EXAFS $1^{\text {st }}$ neighbor signal is reduced to something consistent with a trimer, as demonstrated pictorially in Fig. 9.

\subsection{Discussion on Pt morphology and catalytic activity}

Comparing catalytic activity of $\mathrm{Pt}$ on $\gamma-\mathrm{Al}_{2} \mathrm{O}_{3}$ catalysts is complicated by its dual nature. Typically, the role of the $\mathrm{Pt}$ cluster and the support are thought to be independent with Pt clusters providing hydrogen whereas the alumina provides acid sites for ring opening. Both the cluster size and morphology and the alumina surface change due to catalyst formulation and operating conditions. In this review, we have found that the Pt clusters can be three dimensional or biplanar morphology with varying sizes. Two key factors in determining the Pt cluster morphology are the drying/calcination conditions prior to reduction and the final reduction temperature. Drying/calcining the support reduces the mobility of the Pt by decomposing the initial precursor and removing water and hydroxyls from the alumina support. The final reduction temperature can further increase the $\mathrm{Pt}-\mathrm{Al}_{2} \mathrm{O}_{3}$ support interaction causing biplanar morphology and disorder in the Pt cluster (Fig. 9). There are two effects on catalytic reactions (1) changes in Pt cluster morphology change the atomic structure of the active Pt sites and (2) changes in the support interaction cause changes in electronic density of Pt.

For Pt on $\gamma-\mathrm{Al}_{2} \mathrm{O}_{3}$ catalysts, there is a decrease in hydrogenolysis selectivity of both neopentane and methylcyclopentane to methane after HT reduction relative to LT reduction [17]. The turn over frequency (TOF) which includes isomerization, ring-opening and hydrogenolysis activity increases by a factor of 2.5 after HT relative to LT reduction. This modest increase is attributed to changes in the Pt chemistry rather than changes in the acidity of the alumina support, which generally result in orders of magnitude changes in TOF. Vaarkamp et al. [17] attributed the increase in isomerization activity to the change in morphology of the Pt particles by comparing results with single crystal experiments, while the change in hydrogenolysis activity was attributed to electronic effects changing the Pt partial oxidation state caused by strong interaction of the support.

Hydrogenolysis of methylcyclopentane was compared on $\mathrm{Pt}$ $\gamma-\mathrm{Al}_{2} \mathrm{O}_{3}$ catalyst with different hydrogen pretreatments [43]. These catalysts were prepared by calcination at $400{ }^{\circ} \mathrm{C}$ followed by reduction in $\mathrm{H}_{2}$ to $275^{\circ} \mathrm{C}$ (LTR) or $400{ }^{\circ} \mathrm{C}$ (HTR). It was found that high temperature of $400{ }^{\circ} \mathrm{C}$ decreased hydrogenolysis activity of highly dispersed catalyst compared to oth- 
ers and that overall activity was lower after HT treatment as compared to lower temperature treatment of $275^{\circ} \mathrm{C}$. The selectivity shift to less n-hexane after HTR was attributed to changes in the partial Pt oxidation state becoming more positively charged with increasing support interaction [43].

Another study of hydrogen pretreatments on the hydrogenolysis of $n$-pentane and $n$-hexane found similar trends that hydrogenolysis was suppressed and isomerization increased after high temperature $\mathrm{H}_{2}$ treatment of $600{ }^{\circ} \mathrm{C}$ compared to $400{ }^{\circ} \mathrm{C}$ [16]. The catalyst was commercial CK 306 grade $(0.6 \% \mathrm{Pt}$ on $\gamma-\mathrm{Al}_{2} \mathrm{O}_{3}$ ) of Ketjen Catalysts. This study found the loss in activity after high temperature treatments to be reversible with oxidation treatment at $500{ }^{\circ} \mathrm{C}$ for $1 \mathrm{~h}$. This study makes the comparison of high temperature $\mathrm{H}_{2}$ treatment as resulting in the same affects as chloriding and sulfding the catalyst, suggesting a poisoning of the active Pt sites for hydrogenolysis.

Hydrogen can bind strongly to Pt at high temperature decreasing hydrogen chemisorption and hydrogenolysis $[12,15,16,19]$. The Pt cluster morphology changes from more three dimensional after LT reduction to more biplanar after HT reduction. The metallic nature of Pt decreases for a biplanar morphology as more Pt atoms within the cluster participate in direct bonding with $\mathrm{O}$ of the support. Both the Pt and $\mathrm{O}$ become electronically depleted with the neighboring aluminum atom gaining electrons $[24,38]$. The negatively charged Pt atoms can be satisfied with the adsorption of $\mathrm{H}$. This complicated interplay between support and Pt cluster can make the interpretation of performance differences difficult. In addition, high hydrogen coverage alone has been shown to transform biplanar Pt clusters with large negative charge to cuboctahedral (3-dimensional) morphology with nearly neutral Pt atom charge [38]. The evidence collected here suggests that very small Pt clusters and/or clusters with biplanar morphology, where large number of the Pt atoms are in strong contact with the support, may not be preferred for maximizing hydrogenolysis reactions. Fortunately, catalytic reforming processes desire to minimize hydrogenolysis reactions that produce light hydrocarbons with low-octane value.

\section{Catalysis fundamentals of metal sulfides for hydroprocessing}

Transition metal sulfides, particularly those of the Group VI metals Mo and W, play an important role in industrial catalysis, for hydroprocessing of feedstocks high in sulfur and nitrogen contents. Their principal roles are for providing the hydrogenation function and for converting heteroatom species, mainly $\mathrm{N}$ and S compounds, in hydrotreating and hydrocracking. As such, the chemistry of Mo and W sulfides has long been a focus of industrial and academic research. Mo and W form isostructural layered disulfides having sheets with trigonal symmetry and weak van der Waals bonds between adjacent sheets. It has long been known that the undisturbed trigonal basal plane of $\mathrm{MoS}_{2}$, due to its saturated bonds, interacts too weakly with hydrocarbon or heteroatom species to be catalytically active $[44,45]$. Rather, it is the reactive edge sites which catalyze hydrogenation and heteroatom reactions [46]. Sulfur decoration of edges of metal sulfide sheets is of central importance to the catalytic sites, as has long been recognized. In the early 1970s using reaction rate sensitivity to feed sulfur, Voorhoeve and Struiver proposed that the active sites in $\mathrm{Ni}-\mathrm{W}$ sulfides for hydrogenation of simple hydrocarbons are sulfur deficient surface sites of the Mo and W metal sulfide [47], so-called coordinatively unsaturated (CUS) sites. The sensitivity of reaction rates over $\mathrm{MoS}_{2}$ to feed sulfur has often been reproduced, and may be observed for example in the hydrogenation of toluene [48]. It has also been found that reductive pretreatment of supported $\mathrm{MoS}_{2}$ in hydrogen can improve catalyst activity for hydrogenation of isoprene, which can be explained via generation of more CUS edge sites [49,50]. While the importance of sulfur-deficient CUS sites for saturating hydrocarbons is not disputed, other studies have suggested that these are not the only catalytically important sites, and that sulfur-rich sites may show improved activity, particularly for removal of thiophene $[51,52]$. The direct participation of labile forms of sulfur in HDS reactions has also been demonstrated by isotopic exchange studies using ${ }^{35} \mathrm{~S}$ $[53,54]$. The central importance of edge site chemistry for the Group VI sulfide hydrogenation function also extends to Coand Ni-promotion, which was shown to rely on the promoter atoms' presence substituting for Mo or $\mathrm{W}$ along the edges of sulfide sheets [55-57]. Synthesis of promoted or unpromoted $\mathrm{Mo}(\mathrm{W})$ sulfides for catalysis is generally performed by sulfidation of an oxidic or hydroxide precursor, and it is well known that high dispersion of the precursor phase is critically important for the formation of well-dispersed sulfides. The mechanism and kinetics of the sulfidation reaction has been extensively studied by XPS [58-60], X-ray absorption [60-62], and laser Raman spectroscopy [62]. The sulfidation process and properties of the resulting sulfide nanoparticles have been shown to depend on support composition [63] and heat treatment [64], the sulfiding agent used [65], use of catalyst additives such as phosphorus or chelating agents $[60,61]$ and reactor pressure and temperature $[65,66]$. While the oxidic precursor and sulfidation conditions can strongly influence details of sulfide structure and catalytic activity, the focus of the current work is on the fundamentals of $\mathrm{Co}(\mathrm{Ni}) \mathrm{Mo}(\mathrm{W}) \mathrm{S}_{2}$ edge site chemistry, and the methods which can be used to gain insight into the nature of these sites. In the following section, we will provide a brief review of characterization aimed at determining the amount and speciation of edge-site sulfur in promoted and unpromoted Mo and W sulfides, as well as of known properties of the sulfides for activating hydrogen. For a more extensive review of work prior to 2002, the reader is referred to the review of Breysse et al. [67].

\subsection{Review of sulfur interactions with catalytic $\mathrm{Mo}(W) S_{2}$}

Given the sensitivity of hydrocarbon reaction rates to sulfur occupancy along edge sites of $\mathrm{Mo}(\mathrm{W}) \mathrm{S}_{2}$, the ability to measure and determine speciation of sulfur attached to edge sites is critical. However, it can be quite challenging to provide such information unambiguously using characterization and modeling techniques.

One popular set of approaches for the study of sulfur inter- 
action with unpromoted or promoted $\mathrm{Mo}(\mathrm{W}) \mathrm{S}_{2}$ involves direct measurement of sulfur uptake and removal from catalysts under thermal treatments with hydrogen using TPR. For example, catalyst reduction in hydrogen after in-situ sulfidation has been studied by TPR by several groups [68-72]. These techniques track hydrogen consumption and $\mathrm{H}_{2} \mathrm{~S}$ evolution during TPR of a catalyst's sulfided form, and are known as TPR-S. Well-designed TPR-S measurements can quantitatively detect sulfur being removed from group VI edge sites, and how it varies with treatment and catalyst composition. Based on the temperature at which they react to form $\mathrm{H}_{2} \mathrm{~S}$, TPR-S can also give an indication of the sulfur bond strengths to the underlying metals. However, interpretation of these measurements can be complicated due to the ability of active metal sulfides and supports to adsorb hydrogen (see below). Also, particularly for the case of catalysts on oxide supports, significant physisorption of $\mathrm{H}_{2} \mathrm{~S}$ can occur [73]. Hence, the $\mathrm{H}_{2} \mathrm{~S}$ evolution from the catalyst may not reliably indicate the removal of edge-site sulfur species. Use of TPR-S to detect and identify species of sulfur on group VI edge sites, and how these depend on composition and treatment, thus requires additional ways of verifying the nature of the sulfur removed in TPR-S.

Useful examples of where complementary techniques have been used for characterization of edge sulfur include XPS and Raman spectroscopy, recently used by Afanasiev [52] to characterize unsupported $\mathrm{MoS}_{2}$ after $400{ }^{\circ} \mathrm{C}$ exposures to pure $\mathrm{H}_{2}$ and $\mathrm{H}_{2} \mathrm{~S}$. For samples given a final treatment in pure $\mathrm{H}_{2} \mathrm{~S}$, XPS spectra for the sulfur $2 p$ states show a high-energy shoulder at a binding energy of $163 \mathrm{eV}$, consistent with edge-decorating $\mathrm{S}_{2}{ }^{2-}$ disulfide ions. Interestingly, this shoulder peak is missing in the $\mathrm{H}_{2}$-activated $\mathrm{MoS}_{2}$. Similarly, by Raman spectroscopy, a vibration at $528 \mathrm{~cm}^{-1}$ was found in the $\mathrm{H}_{2} \mathrm{~S}$ activated material, and was attributed to an S-S vibration of surface-bonded disulfide ions. In catalytic testing of thiophene conversion, the $\mathrm{S}_{2}{ }^{2-}$ ions are reported to further react with $\mathrm{H}_{2}$ to form pairs of Mo-SH groups, resulting in a catalyst state which has higher activity for thiophene conversion by hydrogenation (HYD) mechanism, relative to a hydrogen-activated form. This suggests an enhancement of hydrogenation due to abundant Mo-SH on edge sites of sulfur-rich $\mathrm{MoS}_{2}$, whereas stoichiometric $\mathrm{MoS}_{2}$ resulting from hydrogen pretreatment does not generate equivalent $\mathrm{SH}$-decorated edges during reaction of thiophene, and remains less active overall [52].

Inelastic neutron scattering (INS) experiments have been performed by several authors [74-77]. The measurements are sensitive to vibrations involving hydrogen, which is also abundant as $\mathrm{OH}$ groups on oxide supports, so the most informative of the INS work for determining sulfur speciation in $\mathrm{MoS}_{2}$ and $\mathrm{WS}_{2}$ has been conducted with unsupported microcrystalline sulfides. Spectra collected by Sundberg et al. [77] show a predominant S-H bending frequency of $650 \mathrm{~cm}^{-1}$ in $\mathrm{MoS}_{2}$ after 300 ${ }^{\circ} \mathrm{C}$ exposure to $\mathrm{H}_{2}$ following sulfidation. They propose that this is due to dissociative chemisorption of hydrogen to produce $\mathrm{SH}$ groups on $\mathrm{MoS}_{2}$ edges. While the presence of sulfhydryl groups on $\mathrm{MoS}_{2}$ is clearly indicated, the results do not as clearly identify the locations of the sulfhydryls, specifically whether they involve edge or basal plane sulfur atoms. While the presence at edge sites appears likely the authors do not rule out that some hydrogen may dissociate at edge sites, followed by migration to interact with basal plane sulfur. In agreement with the INS detection of sulfhydryl groups in unsupported $\mathrm{MoS}_{2}$, Komatsu and Hall determined that $\sim 75 \%$ of sorbed hydrogen in microcrystalline $\mathrm{MoS}_{2}$ is detected by ${ }^{1} \mathrm{H}$ NMR in a form consistent with $\mathrm{SH}[78]$.

Lauritsen and co-authors $[55,79,80]$ have studied the structures of promoted and unpromoted $\mathrm{MoS}_{2}$ clusters grown in-situ on Au (111) surfaces using scanning tunneling microscopy (STM). Based on observed structures, for pure $\mathrm{MoS}_{2}$ they propose a $50 \%$ sulfur occupation of the Mo-edge, or (1010) edge, resulting in a 6-fold trigonal prismatic coordination of Mo along the edge, but with the coordination polyhedron rotated and out of registry with respect to the bulk coordination [80]. Exposure to atomic hydrogen generated in-situ in the STM using a hot filament was found able to remove sulfur from $\mathrm{MoS}_{2}$ edge sites [80]. The addition of Co promoter results in a change of morphology to hexagonal, exposing S-edges ((1010) edges), along which Co is substituted at the Mo position, in a tetrahedral coordination. Promotion with Ni resulted in development of two distinct sulfide particle morphologies, one of which is generally analogous to Co-promoted particles, having Ni tetrahedrally coordinated with sulfur in the S-edges, while the other is smaller, and was suggested to have lower sulfur coverage [55].

Topsøe and Topsøe have used Fourier transform infrared spectroscopy (FTIR) to indirectly detect the presence of $\mathrm{SH}$ groups on edges of alumina-supported $\mathrm{MoS}_{2}$ and Co promoted $\mathrm{MoS}_{2}$ [81]. This work has relied on a hydroxyl band at 3600 $\mathrm{cm}^{-1}$, which they attribute to hydroxyls which are hydrogen-bonded and shifted due to interaction with $\mathrm{SH}$ groups on $\mathrm{MoS}_{2}$ edges. This identification is supported by a correlation between the intensity of the $3600 \mathrm{~cm}^{-1}$ band with the total intensity of NO bands after NO adsorption at room temperature, the latter being proportional to the total amount of edge sites. Using this identification, they investigate the impacts of pretreatment and Co promotion on the concentration of edge-site $\mathrm{SH}$ groups. It appears that increasing the temperature of $\mathrm{N}_{2}$ purge after sulfidation results in fewer SH groups, as does addition of cobalt promoter. These results are also supported by pyridine adsorption experiments, which can detect $\mathrm{SH}$ groups as weak Brønsted acids. Additional FTIR using low-temperature $\mathrm{CO}$ adsorption has more recently been used by Chen et al. [82] to assess changes in morphology and sulfur occupancy of supported $\mathrm{MoS}_{2}$, in response to citric acid addition. In addition to detecting an increase in the amount of sulfur-edge with addition of citric acid, this work suggests that sulfur is more strongly bound to this edge than to the molybdenum edge, consistent with fewer vacancies being produced on the sulfur edge by hydrogen treatment. In spite of having fewer vacancies, the S-edge is found to have a higher activity for thiophene conversion than the Mo-edge, due to greater destabilization of the thiophene $\pi$-bond by back-donation, resulting in easier $\mathrm{C}-\mathrm{S}$ bond scission.

Finally, extensive use has been made of EXAFS in the characterization of catalytic metal sulfides [72,83-85]. While EXAFS 
can quantitatively provide bond distances and coordination numbers, the values provided are overall averages for the material studied. Therefore, the ability of conventional EXAFS to provide quantities and speciation of edge-site sulfur is limited, using the absorption edges of Mo and W, since the great majority of these elements will be in the bulk $\mathrm{Mo}(\mathrm{W}) \mathrm{S}_{2}$ phase. This bulk signal can however be used to estimate mean particle extent of $\mathrm{MoS}_{2}$ or $\mathrm{WS}_{2}$ [85]. The limited sensitivity to edge site chemistry does not apply to the case for promoter atoms, which at low concentrations tend to preferentially locate in substitutional edge sites in most active catalysts. Thus, EXAFS is particularly suited to understanding the coordination environments of promoters such as Co and Ni [86,87]. The same consideration is also true for Mössbauer spectroscopy, which was used extensively in early work to determine the promoter sites in $\mathrm{Co}^{-\mathrm{MoS}_{2}}$ catalysts $[57,88]$. In another approach, EXAFS difference analyses, or $\triangle \mathrm{EXAFS}$, using data sets taken bracketing a gas-adsorption treatment, may be used to gain surface-specific changes in coordination due to a reductive or other surface process. This approach provides surface-specific information from EXAFS, in a way which is not limited to the study of promoters. Topsøe et al examined changes in EXAFS qualitatively to detect loss of edge site sulfur due to reduction of $\mathrm{Ni}-\mathrm{MoS}_{2}$. Subsequently, Miller et al used this to quantitatively study coordination changes of Co and Mo due to oxygen chemisorption [84]. We will present more detailed treatment of changes to $\mathrm{MoS}_{2}$ by EXAFS difference spectra due to TPR-S below.

\subsection{Review of Hydrogen Interactions with Catalytic $\mathrm{Mo}(\mathrm{W}) \mathrm{S}_{2}$}

This topic has been extensively reviewed by Breysse et al. for work prior to 2002 [67], and we indicate here only results which have direct bearing on our recent TPR-S and related work presented below. The interaction of hydrogen with promoted and unpromoted catalytic $\mathrm{Mo}(\mathrm{W}) \mathrm{S}_{2}$ is central to the TPR-S technique, where the intent of hydrogen exposure is to react edge site sulfur to $\mathrm{H}_{2} \mathrm{~S}$, and thereby determine quantities of various sulfur species (see previous section). However, the metal sulfides studied may also absorb hydrogen, or provide an entry/exit of hydrogen to access or desorb from an oxide support, so consideration of both effects is important for evaluation of TPR-S results.

For the case of unsupported $\mathrm{MoS}_{2}$ and Ni-promoted $\mathrm{MoS}_{2}$, volumetric adsorption measurements by Sundberg et al. [77] found a total $\mathrm{H}_{2}$ uptake corresponding to $\mathrm{H}_{0.054} \mathrm{MoS}_{2}$, after exposure to pure hydrogen at $200{ }^{\circ} \mathrm{C}$ and ambient pressure, in good agreement with Polz et al. [89]. Total hydrogen uptake decreases at higher temperatures. Ni-promotion of unsupported $\mathrm{MoS}_{2}$ leads to an approximately 3-fold increase in the hydrogen uptake relative to $\mathrm{MoS}_{2}$, but the spectroscopic evidence for $\mathrm{SH}$ is weaker, suggesting that hydrogen populates other Ni-specific sites in unsupported $\mathrm{Ni}^{-\mathrm{MoS}_{2}}$ [77]. For $\mathrm{Ni}$-promoted $\mathrm{MoS}_{2}$ the hydrogen is also much more strongly bound, and significant hydrogen is retained even after desorption at $400{ }^{\circ} \mathrm{C}$. By comparison, unsupported $\mathrm{MoS}_{2}$ desorbs more than $90 \%$ of adsorbed hydrogen under vacuum at $300{ }^{\circ} \mathrm{C}$ [77], in agreement with Polz et al. [89]. The reversibility of the hy- drogen adsorption/desorption discussed by Poltz et al. [89] suggests that the SH groups detected by neutron spectroscopy can decompose and re-form on unsupported $\mathrm{MoS}_{2}$, in response to pumping or hydrogen exposure, at temperatures between about 200 and $300{ }^{\circ} \mathrm{C}$.

Hydrogen adsorption on supported $\mathrm{MoS}_{2}$ shows much higher uptake values than unsupported. This was investigated in experiments by Jalowiecki et al. [90], and Kasztelan et al. [48], who determined the presence of reactive hydrogen on mechanical mixtures of $\mathrm{MoS}_{2}$ /alumina catalyst with alumina, using probe reactions with isoprene or oxygen. They determined that the hydrogen quantity adsorbed by a series of mechanical mixtures with variable catalyst/(catalyst+alumina) extrapolates to a significant non-zero hydrogen for pure alumina. Because pure alumina under the same conditions does not adsorb any reactive hydrogen, this indicates that $\mathrm{MoS}_{2}$ acts as an entry 'gate' for hydrogen, which is able to migrate onto the alumina support 'reservoir' over large distances. There are several possible routes for the hydrogen activation: edge site sulfurs may react with dihydrogen to form pairs of SH groups; a metal CUS site may be involved in a heterolytic reaction producing a metal hydride and SH from a nearby edge sulfur [91]; or $\mathrm{H}_{2}$ may activate heterolytically at a Mo bonded with support oxygen. Once activated and present on $\mathrm{MoS}_{2}$ in SH groups, hydrogen is quite mobile on the sulfide particle. Diffusion onto the alumina support may be facilitated by terminal SH edge groups [92].

With the context provided by this review for interpretation, we now present examples of TPR-S studies of model supported and unsupported metal sulfides, along with EXAFS studies and DFT modeling of selected results.

\subsection{TPR-S measurements on supported mo and unsupported $\mathrm{Ni}-\mathrm{Mo}$-W sulfides}

In this section, we will discuss recent experiments using TPR-S supported by structural analyses using EXAFS and DFT modeling, which illustrate how this technique can contribute to fundamental understanding of metal sulfide catalyzed reactions in hydroprocessing.

Fig. 10 shows the results of two TPR-S experiments carried out at ambient pressure on a sulfided $5 \mathrm{wt} \%$ Mo/alumina support. In both experiments, the sample was pretreated by sulfiding in-situ in a quartz plug-flow reactor at $400{ }^{\circ} \mathrm{C}$ using a $5 \%$ $\mathrm{H}_{2} \mathrm{~S}, 5 \% \mathrm{H}_{2}, 90 \%$ Ar gas blend. For the experiment in Fig. 10(a), the sample was cooled to room temperature in the sulfiding gas blend after pretreatment, purged $30 \mathrm{~min}$ in argon before TPR-S was recorded using $5 \% \mathrm{H}_{2} / \mathrm{Ar}$, at $5^{\circ} / \mathrm{min}$, to $600^{\circ} \mathrm{C}$. The plots shown in Fig. 10(b) show TPR-S for the same sample, but with the pretreatment followed by an argon purge at $400{ }^{\circ} \mathrm{C}$ before cooling. Both mass spectrometer (MS) and thermal conductivity detector (TCD) outputs which monitor the effluent for the experiments are shown, with the latter reflecting the hydrogen consumption in the TPR-S. In the case of Fig. 10(a), there's significant $\mathrm{H}_{2} \mathrm{~S}$ evolution across the entire temperature range. The $\mathrm{H}_{2} \mathrm{~S}$ evolution curve does not correspond to the $\mathrm{H}_{2}$ consumption by the TCD. This suggests that much of the $\mathrm{H}_{2} \mathrm{~S}$ evolution is 

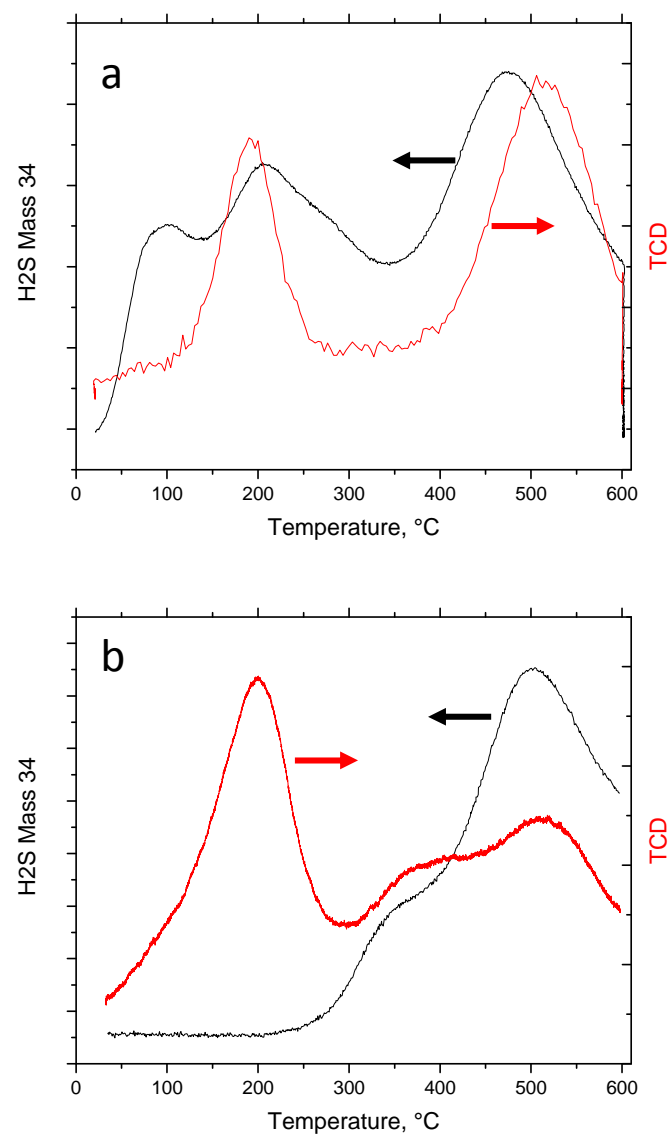

Fig. 10. TPR-S experiments for supported $5 \% \mathrm{Mo} / \mathrm{Al}_{2} \mathrm{O}_{3}$ catalyst. (a) Sample pretreated $1 \mathrm{~h}$ at $400{ }^{\circ} \mathrm{C}$ in $\mathrm{H}_{2} \mathrm{~S} / \mathrm{H}_{2} /$ argon, then cooled to room temperature prior to TPR-S. (b) Sample pretreated as in a) but purged $30 \mathrm{~min}$ in argon at $400{ }^{\circ} \mathrm{C}$ before cooling to room temperature for TPR-S. Red curves are TCD output, which primarily reflects $\mathrm{H}_{2}\left(\mathrm{H}_{2}\right.$ consumption is upward in plots). Black curves are mass spectrometer for $\mathrm{H}_{2} \mathrm{~S}$ ( $\mathrm{H}_{2} \mathrm{~S}$ production is upward in plots).

from physisorbed $\mathrm{H}_{2} \mathrm{~S}$, which has been confirmed by performing the same experiment on the support alone (not shown). Both TPR-S experiments in Fig. 10(a) and 10(b) show a hydrogen consumption event in the TCD signal, with a peak temperature close to $200^{\circ} \mathrm{C}$. In the case of Fig. 10 (b), this is not accompanied by any $\mathrm{H}_{2} \mathrm{~S}$ evolution, and is thus consistent with hydrogen adsorption and spillover onto the support, a phenomenon known to occur, as discussed in the previous section. Note that the TCD signal shown in Fig. 10(b) shows good qualitative agreement with results of McGarvey and Kasztelan [71], however their conclusion that the low-temperature hydrogen consumption corresponds to a reaction producing $\mathrm{H}_{2} \mathrm{~S}$ is not supported by the MS signal in Fig. 10(b). The $\mathrm{H}_{2}$ consumption by supported $\mathrm{MoS}_{2}$ indicated by the TCD curve in Fig. 10(a) may involve either or both of $\mathrm{H}_{2}$ activation and spillover onto the support, or reaction and removal of edge site sulfur to form $\mathrm{H}_{2} \mathrm{~S}$. This reaction was investigated by EXAFS as described below, and was determined to arise at least in part from the removal of sulfur from edge sites of $\mathrm{MoS}_{2}$. This $\mathrm{H}_{2} \mathrm{~S}$ evolution from reaction of $\mathrm{H}_{2}$ to form $\mathrm{H}_{2} \mathrm{~S}$ is obscured in the TPR-S data of
Fig. 10(a) by the evolution of copious physisorbed $\mathrm{H}_{2} \mathrm{~S}$.

Further insight into the results shown in Fig. 10(a) are provided by TPR-S analyses of an unsupported Ni-Mo-W model catalyst. Using the same pretreat and TPR conditions as in Fig. 10(a) with an unsupported Ni-Mo-W catalyst, the $\mathrm{H}_{2} \mathrm{~S}$ MS and TCD signals show strong conformity with each other, having almost identical shapes. This suggests that the generation of $\mathrm{H}_{2} \mathrm{~S}$ and consumption of $\mathrm{H}_{2}$ are linked, and that the predominant interaction is $\mathrm{H}_{2}$ from the reduction gas reacting with sulfur from the sample to form $\mathrm{H}_{2} \mathrm{~S}$ gas. Furthermore, for this to be the case, the amount of of physisorbed $\mathrm{H}_{2} \mathrm{~S}$ contributing to the TPR-S for this material must be negligible, in contrast to the supported catalyst. This has been confirmed using a temperature-programmed desorption (TPD) experiment in 100\% $\mathrm{Ar}$ for the unsupported Ni-Mo-W catalyst. After identical pretreatment as in Fig. 10(a), negligible $\mathrm{H}_{2} \mathrm{~S}$ evolution is seen for the Ni-Mo-W unsupported catalyst during a TPD ramp in $100 \%$ Ar. In line with this, using a $400^{\circ} \mathrm{C}$ Ar purge after pretreatment, as in Fig. 10(b), has a rather minor effect on the TPR-S, with slightly less $\mathrm{H}_{2} \mathrm{~S}$ evolution below about $300{ }^{\circ} \mathrm{C}$, and a small mismatch between $\mathrm{H}_{2}$ consumption and $\mathrm{H} 2 \mathrm{~S}$ evolution in this temperature range suggestive of some hydrogen adsorption $[89,93]$. For the Ni-Mo-W unsupported sulfide, a low-temperature peak in $\mathrm{H}_{2}$ uptake and $\mathrm{H}_{2} \mathrm{~S}$ evolution is seen in the TPR-S at $\sim 230^{\circ} \mathrm{C}$, which is similar to the $\sim 200{ }^{\circ} \mathrm{C} \mathrm{H}_{2}$ uptake in the supported $\mathrm{MoS}_{2}$ catalysts shown in Fig. 10. By running repeat cycles of reduction and re-sulfidation over this peak, up to a temperature of $250{ }^{\circ} \mathrm{C}$, we have found that the peak represents a form of sulfur which can be replaced and removed repeatedly without irreversibly changing the material. This suggests that it represents surface sulfur corresponding to sulfur ligands on active sites. Above $300{ }^{\circ} \mathrm{C}$, the TPR-S experiments on the unsupported sample show additional $\mathrm{H}_{2} \mathrm{~S}$ evolution/ $\mathrm{H}_{2}$ consumption peaks, which are not reversible by re-sulfidation up to $400{ }^{\circ} \mathrm{C}$. Correspondingly, XRD analyses of sample retains from TPR-S to $600^{\circ} \mathrm{C}$ show bulk microstructural changes in the unsupported catalyst.

The low-temperature reactions detected in the TPR-S results above provide insights into the interaction of sulfur with the edge sites of $\mathrm{MoS}_{2}$ and $(\mathrm{Mo}, \mathrm{W}) \mathrm{S}_{2}$. This interaction is the central factor determining the types and abundance of CUS sites, which are known to contribute to catalytic activity in hydroprocessing. This suggests that metal function activity should be related to the peak temperature for reactive desorption of sulfur in TPR-S. Previous authors have successfully linked catalytic activity to the inverse of the metal-sulfur bond energy in the sulfides, with the bond energy model (BEM) of Topsøe et al. [72]. In line with this, the promoting effect of $\mathrm{Co}$ and $\mathrm{Ni}$ in $\mathrm{MoS}_{2}$ is related to its lowering of the surface metal-sulfur bond strength in the promoted sulfides. Thus, the reaction temperature for removal of weakly-bound surface sulfur in TPR-S is lower in both Co-Mo and Ni-Mo sulfides than the same reaction in any of the pure metal sulfides [72].

\subsection{EXAFS difference analysis and DFT modeling of TPR-S edge-site sulfur}


While the ability of $\mathrm{MoS}_{2}$ to activate and spill hydrogen onto alumina has long been known $[48,89,90]$, direct detection of edge-site sulfur is more challenging. The reversible removal and replacement of weakly-bound surface sulfur by TPR-S provides an opportunity to characterize this sulfur spectroscopically, in line with previous authors [52,81]. This was done by repeating the experiment of Fig. 10a while monitoring X-ray absorption at the Mo K edge before and after reactive desorption of weakly-bound sulfur. Fig. 11 shows an EXAFS difference spectrum in which the signal at room temperature after re-sulfidation to $450{ }^{\circ} \mathrm{C}$ has been subtracted from the signal at room temperature after sulfur strip to $250{ }^{\circ} \mathrm{C}$. The sulfur strip procedure followed the TPR-S pretreat procedure used in Fig. 10 (a) with a ramp to $250^{\circ} \mathrm{C}$ in $\mathrm{H}_{2} / \mathrm{He}$ blend with a 30 min hold followed by cooling to room temperature in the same gas blend. The re-sulfided and sulfur-stripped spectra (data not shown) are very similar and modeled with the standard $\mathrm{MoS}_{2}$ structure. A bulk like $\mathrm{MoS}_{2}$ structure has each Mo atom coordinated by 6 $\mathrm{S}$ and $6 \mathrm{Mo}$ atoms at distances of 2.41 and $3.17 \AA$, respectively, in a hexagonal lattice as shown in the interior of Fig. 12. The EXAFS CN and bond distances for the room temperature spectrum after re-sulfidation are $6.4 \pm 0.3$ at $2.407 \pm 0.002 \AA$ for $\mathrm{S}$ and $4.2 \pm 0.6$ at $3.157 \pm 0.003 \AA$ for Mo. These results give some important insights into the average Mo coordination environment. On the average, each Mo atom is fully coordinated by $6 \mathrm{~S}$ atoms at the nominal distance. The Mo CN is reduced from 6 in bulk $\mathrm{MoS}_{2}$ to $4.2 \pm 0.6$, suggesting coherent $\mathrm{MoS}_{2}$ cluster containing 19 Mo atoms. AC-STEM of the same sample shows larger $\mathrm{MoS}_{2}$ sheets with a mean extent of just under $30 \AA$, whereas the 19-atom cluster would be only about half of that. The apparent discrepancy between AC-STEM and EXAFS for MoS cluster size has been noted before and is likely due to disorder in the extended structures [85]. Modeling of the EXAFS spectra after sulfur strip results in similar parameters with no change outside the measured uncertainties. In contrast, the difference spectrum shows a clear EXAFS signal consistent with a change of the average Mo coordination with sulfur. Detailed modeling

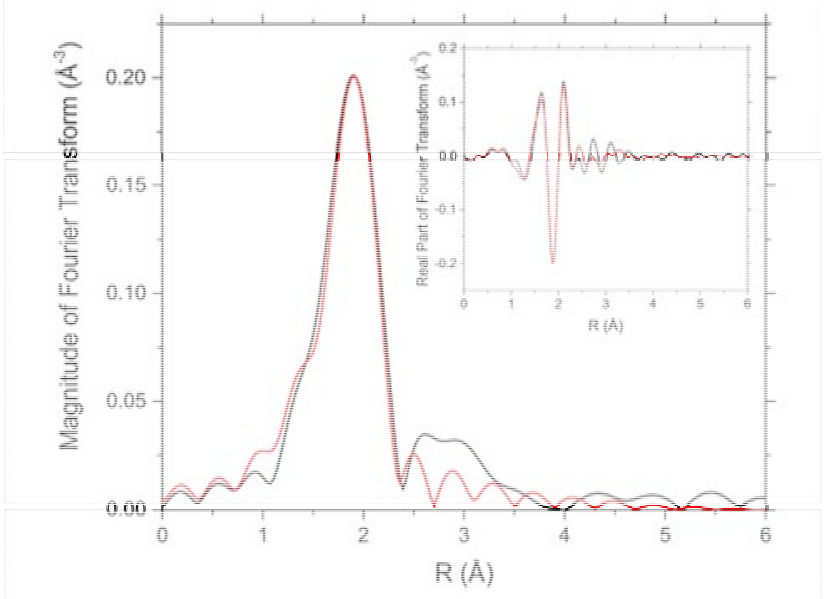

Fig. 11. XAFS difference spectrum for sulfided $5 \% \mathrm{Mo} / \mathrm{Al}_{2} \mathrm{O}_{3}$ catalyst. The plot shows the magnitude of $c(\mathrm{R})$ representing the difference in the radial function before and after mild reduction to $250{ }^{\circ} \mathrm{C}$ in $\mathrm{H}_{2} /$ argon gas blend. Modeled spectrum is in red.

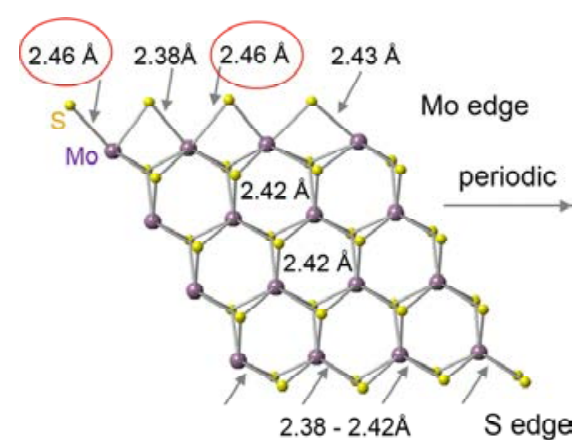

Fig. 12. The stripe model of $\mathrm{MoS}_{2}$ optimized with DFT calculations (VDW density functional with optPBE, PAW_PBE pseudopotentials, 400 $\mathrm{eV}$ cutoff for plane wave basis sets, structural optimization converged at $0.03 \mathrm{eV} / \AA ̊$ max force on each atom, implemented in VASP).

of the EXAFS difference spectrum in Fig. 11 determined that the sulfur strip resulted in a decrease in the average Mo coordination by sulfur of $0.6 \pm 0.1$ sulfur atoms at distance of $2.46 \pm 0.01$ $\AA$, relative to the re-sulfided sample spectrum. This bond length is longer than both the average Mo-S bond length $(\sim 2.41 \AA)$ in the basal plane, and the EXAFS modeling results for the spectra before and after the sulfur strip at $2.407 \pm 0.002 \AA$, suggesting that the $\mathrm{S}$ atom could be removed from a special location. With DFT calculations, the edge and basal plane structures of $\mathrm{MoS}_{2}$ under various reaction conditions has been well studied [82,94-99]. In general, the S edge tends to maintain a much higher $S$ coverage than the Mo edge. Both experiments [80] and our DFT calculations show that it is possible for the Mo edge with lower S coverage to have longer Mo-S bonds. In Fig. 12, the stripe model of $\mathrm{MoS}_{2}$ shows the estimate of edge structures under $\mathrm{H}_{2}$ rich conditions, in which the Mo-S bond length in the Mo edge displays variation, with the longer bonds at $2.46 \AA$. This is in line with what EXAFS difference study in Fig. 11 suggests. Our DFT calculations also suggest that it should be easier to remove $\mathrm{S}$ from the Mo edge than from the S edge. Therefore, it rationalizes the hypothesis that the weakly-bonded sulfur observed in TPR-S indeed comes from the edges (and most likely from Mo edges).

To test the EXAFS difference spectra results indicating the loss of $0.6 \pm 0.1$ sulfur atoms, we constructed an idealized hexagonal cluster of 19 Mo atoms. The hexagonal structure has alternating Mo and S edges. The Mo edge and corner sites make up a total of 9 Mo atoms. A drop from 100\% Mo-edge coverage to $50 \%$ coverage causes the average S CN to drop from 6 (full coverage) to 5.5 ( $50 \%$ coverage) which is in remarkable agreement with the EXAFS measured loss of $0.6 \pm 0.1$ sulfur atoms.

\section{Conclusion and perspective}

For modern refining and petrochemical industry, the catalyst is really the key to unlocking the value of crude oil. Driven by the desire of being more profitable and environmentally friendly, refiners require less expensive, more active and selective catalysts. This imposes significant challenges on catalysis science. Catalyst design and development relies, more than 
ever, on fundamental understanding of the underlying physics and chemistry as a basis of improving catalyst design to target specific product molecules. Advancements in modern analytical science along with molecular modeling have brought new and cohesive insights for many catalytic systems, and this is demonstrated by the two examples shown herein.

Briefly, Pt is arguably the most important noble metal element for refining. Due to its scarcity and high cost, effective usage of every single Pt atom in the catalyst is highly desirable. Although still a long way to go, the amount of Pt on reforming catalysts has been significantly reduced over the years owing to improved understanding of how Pt acts within a given catalyst. Analyses using EXAFS and other analytical approaches clearly show that the Pt cluster size and morphology, which are key factors determining catalytic activity, strongly depend on preparation procedures such as the choice of platinum precursor, pre-treatment condition, and reduction temperature. It appears that interaction of Pt with the support induced during catalyst preparation reduces the Pt mobility leading to smaller Pt clusters, which is confirmed by STEM imaging and molecular modeling. With this understanding in mind, the strength of the support interaction can be tuned to provide optimized catalytic activity and selectivity of the Pt clusters in their roles as centers of dehydrogenation and other transformations of hydrocarbon molecules.

As the world moves more and more towards clean fuels, hydroprocessing has increasingly grown in importance. Transition metal sulfides are main ingredients of finished hydroprocessing catalysts, not only to provide hydrogenation function but also to remove heteroatom (e.g., $\mathrm{N}$ and $\mathrm{S}$ ) species. Many techniques such as FTIR, Raman, NMR, TPR, TPR-S, XAS, XPS, INS, STM, STEM and molecular modeling have been devoted to studying the interactions of sulfur and hydrogen with metal sulfides, which is tightly associated with their catalytic behaviors. Simultaneous detection of $\mathrm{H}_{2}$ consumption and $\mathrm{H}_{2} \mathrm{~S}$ evolution has allowed us to better distinguish and quantify phenomena of physisorbed $\mathrm{H}_{2} \mathrm{~S}, \mathrm{H}_{2}$ activation and spillover onto the support, and of the interactions of edge site sulfur which determine the formation of CUS sites. The EXAFS difference analysis has been able to reveal the subtle change of Mo coordination environment after sulfur stripping, a spectroscopic way to directly confirm the nature of the sulfur removed by TPR-S, and to measure catalytically active edge sites.

Although significant progress has been made, many questions remain on fundamentals of various catalytic functions. This includes better quantification and structure determination of Pt nanoparticles interacting with supports and its impact on catalysis and diffusion; the structures and occupancies of promoters (e.g., Ni or Co) decorating metal sulfide sheets and edge sites in real catalyst; and how to examine macro and micro catalytic behavior under industrial process conditions. No single characterization technique can resolve all the challenges. Integration of multiple tools, including molecular modeling, is imperative to develop next generation catalysts. Furthermore, as digitization becomes a daily routine and computation power is no longer a bottleneck, implementation of data science on catalyst discovery presents an important new opportunity.
Finally, an effective catalyst testing strategy is essential to fully take advantage of what modern analytical techniques can offer.

\section{Acknowledgment}

We express our appreciation to Sohini Basu, Meghan Charochak, George Mickelson, Paolo Moreschini, Susan Tonnesen, Ankit Vishnoi and many other colleagues for their assistance with analytical characterization and/or for their insightful discussions. We also wish to acknowledge support from Honeywell UOP management for permission to publish this manuscript. MRCAT operations are supported by the Department of Energy and the MRCAT member institutions. This research used resources of the Advanced Photon Source, a U.S. Department of Energy (DOE) Office of Science User Facility operated for the DOE Office of Science by Argonne National Laboratory under Contract No. DE-AC02-06CH11357.

\section{References}

[1] V. Haensel, US 2479109, 1949.

[2] V. Haensel, US 2479110, 1949.

[3] H. Taghvaei, M. M. Shirazi, N. Hooshmand, M. R. Rahimpour, A. Jahanmiri, Appl. Energy, 2012, 98, 3-10.

[4] M. R. Rahimpour, M. Jafari, D. Iranshahi, Appl. Energy, 2013, 109, 79-93.

[5] A. Aitani, Catalytic Naphtha Reforming, Encycl. Chem. Process, 2006, 4940

[6] J. E. Mondloch, E. Bayram, R.G. Finke, J. Mol. Catal. A, 2012, 355, $1-38$.

[7] S. E. Wanke, P.C. Flynn, Catal. Rev. Sci. Eng., 1975, 12, 93-135.

[8] J. J. F. Scholten, A. P. Pijpers, A. M. L. Hustings, Catal. Rev. Sci. Eng., 1985, 27, 151-206.

[9] R. A. Herrmann, S. F. Adler, M. S. Goldstein, R. M. Debaun, J. Phys. Chem., 1961, 65, 2189-2194.

[10] L. Spenadel, M. Boudart, J. Phys. Chem., 1960, 64, 204-207.

[11] F. Behafarid, L. K. Ono, S. Mostafa, J. R. Croy, G. Shafai, S. Hong, T. S. Rahman, S. R. Bare, B. Roldan Cuenya, Phys. Chem. Chem. Phys., 2012, 14, 11766-11779.

[12] M. K. Oudenhuijzen, J. H. Bitter, D. C. Koningsberger, J. Phys. Chem. $B, \mathbf{2 0 0 1}, 105,4616-4622$.

[13] F. J. Gracia, J. T. Miller, A. J. Kropf, E. E. Wolf, J. Catal., 2002, 209, 341-354.

[14] J. R. Chang, S. L. Chang, T. B. Lin, J. Catal., 1997, 169, 338-346.

[15] P. G. Menon, G. F. Froment, J. Mol. Catal., 1984,25, 59-66.

[16] P. G. Menon, G. F. Froment, J. Catal., 1979, 59, 138-147.

[17] M. Vaarkamp, J. T. Miller, F. S. Modica, D. C. Koningsberger, J. Catal., 1996, 163, 294-305.

[18] J. Margitfalvi, P. Szedlacsek, M. Hegedüs, F. Nagy, Appl. Catal., 1985, 15, 69-78.

[19] G. J. Den Otter, F.M. Dautzenberg, J. Catal. 1978, 53, 116-125.

[20] H. Dexpert, J. Phys., 1986, 47, 219-226.

[21] R. B. Greegor, F. W. Lytle, J. Catal., 1980, 43, 465-486.

[22] W. Sinkler, S. I. Sanchez, S. A. Bradley, J. Wen, B. Mishra, S. D. Kelly, S. R. Bare, ChemCatChem, 2015, 7, 3779-3787.

[23] S. A. Bradley, W. Sinkler, D. A. Blom, W. Bigelow, P. M. Voyles, L. F. Allard, Catal. Lett., 2012, 142, 176-182.

[24] C. Mager-Maury, G. Bonnard, C. Chizallet, P. Sautet, P. Raybaud, ChemCatChem, 2011, 3, 200-207.

[25] C. Mager-Maury, C. Chizallet, P. Sautet, P. Raybaud, ACS Catal., 


\section{Graphical Abstract}

Chin. J. Catal., 2019, 40: 1637-1654 doi: S1872-2067(19)63372-3

\section{Advanced characterization for industrial catalysis applications}

Shelly Kelly *, Wharton Sinkler *, Lijun Xu, Sergio Sanchez, Cem Akatay, Haiyan Wang, John Qianjun Chen Honeywell UOP, USA

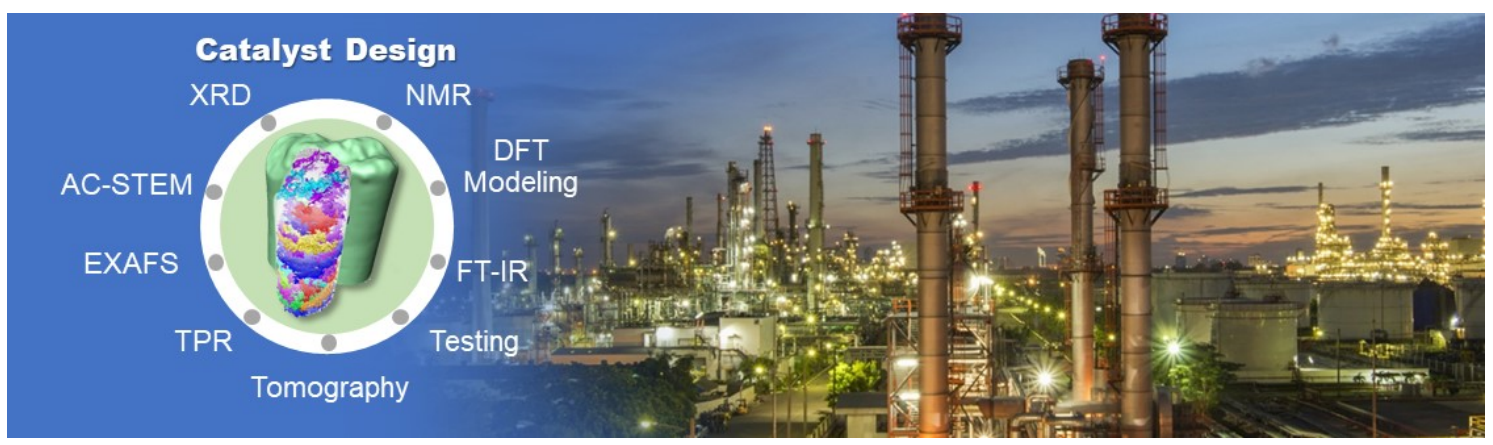

Surface and bulk chemistry characterization is reviewed for two major catalytic functions: Supported Pt nano-clusters and layered Group VI sulfides. Trends are identified relating structure with catalytic activity, and areas for improvement.

2012, 2,1346-1357.

[26] J. Lynch, Oil Gas Sci. Technol., 2002, 57, 281-305.

[27] H. Mistry, F. Behafarid, S. R. Bare, B. Roldan Cuenya, ChemCatChem, 2014, 6,348-352.

[28] N. Tian, Z.-Y. Zhou, S.-G. Sun, Y. Ding, Z. L. Wang, Science, 2007, $316,732$.

[29] M. Digne, P. Sautet, P. Raybaud, P. Euzen, H. Toulhoat, J. Catal., 2002, 211,1-5.

[30] V. P. Pakharukova, D. A. Yatsenko, E. Y. Gerasimov, A. S. Shalygin, O. N. Martyanov, S. V Tsybulya, J. Solid State Chem., 2017, 246, 284-292.

[31] H. P. Pinto, R. M. Nieminen, S. D. Elliott, Phys. Rev. B, 2004, 70, 125402.

[32] X. Krokidis, P. Raybaud, A. E. Gobichon, B. Rebours, P. Euzen, H. Toulhoat, J. Phys. Chem., 2001,105, 5121-5130.

[33] F. Le Normand, S. Bazin, H. Dexpert, P. Lagarde, J. P. Bournonville, in: M. J. Phillips, M. Ternan (Eds.), Proc. 9th Int. Conf. Catal., The Chemical Institue of Canada, Ontario, Canada, 1988,1401-1412.

[34] A. Munoz-Paez, D. C. Koningsberger, J. Phys. Chem., 1995, 99, 4193-4204.

[35] P. Lagarde, T. Murata, G. Vlaic, E. Freund, H. Dexpert, J. P. Bournonville, J. Catal., 1983, 84, 333-343.

[36] G. H. Via, J. H. Sinfelt, F. W. Lytle, J. Chem. Phys., 1979, 71, 690-699.

[37] P. D. Nellist, S. J. Pennycook, Science, 1996, 274,413-415.

[38] C. H. Hu, C. Chizallet, C. Mager-Maury, M. Corral-Valero, P. Sautet, H. Toulhoat, P. Raybaud, J. Catal., 2010, 274, 99-110.

[39] D. Bazin, H. Dexpert, J. P. Bournonville, J. Lynch, J. Catal., 1990, 123, 86-97.

[40] D. C. Koningsberger, D. E. Sayers, Solid State Ionics, 1985, 16, 23-27.

[41] C.-B. Wang, H.-K. Lin, S.-N. Hsu, T.-H. Huang, H.-C. Chiu, J. Mol. Catal. A, 2002, 188, 201-208.

[42] E. Bus, J. T. Miller, A. J. Kropf, R. Prins, J. A. Van Bokhoven, Phys. Chem. Chem. Phys., 2006, 8, 3248-3258.

[43] R. Kramer, M. Fischbacher, J. Mol. Catal., 1989, 51, 247-259.

[44] M. Salmeron, G. A. Somorjai, A. Wold, R. Chianelli, K. S. Liang, Chem.
Phys. Lett., 1982, 90, 105-107.

[45] R. R. Chianelli, Catal. Rev. Sci. Eng., 1984, 26, 361-393.

[46] S. Kasztelan, H. Toulhoat, J. Grimblot, J. P. Bonnelle, Appl. Catal., 1984, 13, 127-159.

[47] R. J. H. Voorhoeve, J. C. M. Struiver, J. Catal., 1971, 23, 228-235.

[48] S. Kasztelan, G. B. McGarvey, J. Catal., 1994, 147, 476-483.

[49] S. Kasztelan, L. Jalowiecki, A. Wambeke, J. Grimblot, J. P. Bonnelle, Bull. Des Soc. Chim. Belges., 1987, 96, 1003-1008.

[50] A. Wambeke, L. Jalowiecki, S. Kasztelan, J. Grimblot, J. P. Bonnelle, J. Catal., 1988, 109, 320-328.

[51] H. Farag, K. Sakanishi, M. Kouzu, A. Matsumura, Y. Sugimoto, I. Saito, Catal. Commun., 2003, 4, 321-326.

[52] P. Afanasiev, J. Catal., 2010, 269, 269-280.

[53] M. Dobrovolszky, P. Tetenyi, Z. Paal, Chem. Eng. Commun., 1989, 83, 1-8.

[54] T. Kabe, W. Qian, S. Ogawa, A. Ishihara, J. Catal., 1993, 143, 239-284.

[55] J. V Lauritsen, J. Kibsgaard, G. H. Olesen, P. G. Moses, B. Hinnemann, S. Helveg, J. K. Nørskov, B. S. Clausen, H. Topsøe, E. Lægsgaard, F. Besenbacher, J. Catal., 2007, 249, 220-233.

[56] N. Y. Topsøe, H. Topsøe, J. Catal., 1983, 84, 386-401.

[57] H. Topsøe, B. S. Clausen, R. Candia, C. Wivel, S. Mørup, J. Catal., 1981, 68, 433-452.

[58] T. Weber, J. C. Muijsers, J. H. M. C. Van Wolput, C. P. J. Verhagen, J. W. Niemantsverdriet, J. Phys. Chem., 1996, 100, 14144-14150.

[59] A. J. Van Der Vlies, G. Kishan, J. W. Niemantsverdriet, R. Prins, T. Weber, J. Phys. Chem. B, 2002, 106, 3449-3457.

[60] L. Van Haandel, G. M. Bremmer, E. J. M. Hensen, T. Weber, J. Catal., 2016, 342, 27-39.

[61] D. Nicosia, R. Prins, J. Catal., 2005, 231, 259-268.

[62] A. Rochet, B. Baubet, V. Moizan, E. Devers, A. Hugon, C. Pichon, E. Payen, V. Briois, J. Phys. Chem. C, 2017, 121, 18544-18556.

[63] R. G. Leliveld, A. J. Van Dillen, J. W. Geus, D. C. Koningsberger, J. Catal., 1997, 171, 115-129.

[64] H. R. Reinhoudt, Y. Van Der Meer, A. M. Van Der Kraan, A. D. van Langeveld, J. A. Moulijn, Fuel Process. Technol., 1999, 61, 43-54. 
[65] L. Van Haandel, E. J. M. Hensen, T. Weber, Catal. Today, 2017, 292, 51-57.

[66] Y. Okamoto, A. Kato, N. Rinaldi, T. Fujikawa, H. Koshika, I. Hiromitsu, T. Kubota, J. Catal., 2009, 265, 216-228.

[67] M. Breysse, E. Furimsky, S. Kasztelan, M. Lacroix, G. Perot, Catal. Rev. - Sci. Eng., 2002, 44, 651-735.

[68] B. Scheffer, P. J. Mangnus, J. A. Moulijn, J. Catal., 1990, 121, 18-30.

[69] R. C. Hoodless, R. B. Moyes, P. B. Wells, Bull. Des Soc. Chim. Belges., 1984, 93, 673-679.

[70] P. J. Mangnus, A. Riezebos, A. D. van Langeveld, J. A. Moulijn, J. Catal., 1995, 151, 178-191.

[71] G. B. McGarvey, S. Kasztelan, J. Catal., 1994, 148, 149-156.

[72] H. Topsøe, B. S. Clausen, N. Y. Topsoe, J. K. Nørslov, C. V. Ovesen, C. J. H. Jacobsen, Bull. Des Soc. Chim. Belges., 1995, 104, 283-291.

[73] P. Arnoldy, J. A. M. van den Heijkant, G. D. de Bok, J. A. Moulijn, J. Catal. 1985, 92, 35-55.

[74] C. J. Wright, C. Sampson, D. Fraser, R. B. Moyes, P. B. Wells, C. Riekel, J. Chem. Soc. - Faraday Trans., 1980, 76, 1585-1598.

[75] C. J. Wright, D. Fraser, R. B. Moyes, P. B. Wells, Appl. Catal., 1981, 1, 49-58.

[76] P. N. Jones, E. Knözinger, W. Langel, R. B. Moyes, J. Tomkinson, Surf. Sci., 1988, 207, 159-176.

[77] P. Sundberg, R. B. Moyes, J. Tomkinson, Bull. Des Soc. Chim. Belges., 1991, 100, 967-976.

[78] T. Komatsu, W. K. Hall, J. Phys. Chem., 1991, 95, 9966-9974.

[79] J. V. Lauritsen, S. Helveg, E. Laegsgaard, I. Stensgaard, B. S. Clausen, H. Topsøe, F. Besenbacher, J. Catal., 2001, 197, 1-5.

[80] S. Helveg, J. V Lauritsen, E. Lægsgaard, I. Stensgaard, J. K. Nørskov, B. S. Clausen, H. Topsøe, F. Besenbacher, Phys. Rev. Lett., 2000, 84, 951-954.

[81] N. Y. Topsøe, H. Topsøe, J. Catal., 1993, 139, 641-651.
[82] J. Chen, F. Maugé, J. El Fallah, L. Oliviero, J. Catal., 2014, 320, 170-179.

[83] S. D. Kelly, N. Yang, G. E. Mickelson, N. Greenlay, E. Karapetrova, W. Sinkler, S. R. Bare, J. Catal., 2009, 263, 16-33.

[84] J. T. Miller, C. L. Marshall, A. J. Kropf, J. Catal., 2001, 202, 89-99.

[85] T. Shido, R. Prins, J. Phys. Chem. B, 1998, 102, 8426-8435.

[86] S. P. A. Louwers, R. Prins, J. Catal., 1992, 133, 94-111.

[87] S. P. A. Louwers, R. Prins, J. Catal., 1993, 139,525-539.

[88] C. Wivel, R. Candia, B. S. Clausen, S. Mørup, H. Topsøe, J. Catal., 1981, 68, 453-463.

[89] J. Polz, H. Zeilinger, B. Müller, H. Knözinger, J. Catal., 1989, 120, 22-28.

[90] L. Jalowiecki, J. Grimblot, J. P. Bonnelle, J. Catal., 1990, 101-108.

[91] A. B. Anderson, Z. Y. Al-Saigh, W. K. Hall, J. Phys. Chem., 1988, 92, 803-809.

[92] E. J. M. Hensen, G. M. H. J. Lardinois, V. H. J. de Beer, J. A. R. van Veen, R. A. van Santen, J. Catal., 1999, 187, 95-108.

[93] X. S. Li, Q. Xin, X. X. Guo, P. Grange, B. Delmon, J. Catal., 1992, 137, 385-393.

[94] L. S. Byskov, J. K. Nørskov, B. S. Clausen, H. Topsøe, J. Catal., 1999, 187, 109-122.

[95] P. Raybaud, J. Hafner, G. Kresse, S. Kasztelan, H. Toulhoat, J. Catal., 2000, 189, 129-146.

[96] H. Schweiger, P. Raybaud, G. Kresse, H. Toulhoat, J. Catal,, 2002, 207, 76-87

[97] J. I. Castello I Vidal, A. Lopez Lillo, Nat. Resour., 1993, 29, 12-16.

[98] F. Besenbacher, M. Brorson, B. S. Clausen, S. Helveg, B. Hinnemann, J. Kibsgaard, J. V. Lauritsen, P. G. Moses, J. K. Nørskov, H. Topsøe, Catal. Today, 2008, 130, 86-96.

[99] A. S. Rosen, J. M. Notestein, R. Q. Snurr, J. Phys. Chem. C, 2018,122, 15318-15329.

\title{
先进表征技术在工业催化中的应用
}

\author{
Shelly Kelly ${ }^{\dagger}$, Wharton Sinkler ${ }^{\dagger}$, Lijun Xu, Sergio Sanchez, Cem Akatay, Haiyan Wang, \\ John Qianjun Chen ${ }^{*}$ \\ 霍尼伟尔环球油品公司，阿尔冈昆东路25号，德斯普兰斯，伊利诺伊州 60016，美国
}

\begin{abstract}
摘要: 分析表征与工业应用技术之间的相互影响对开发石油加工的催化材料一直起着至关重要的作用. 本文着重介绍石 油化工中两类最重要的催化材料: (1)催化重整工艺中广泛使用的负载于氧化铝上的铂纳米颗粒; (2)加氢处理工艺中用于 加氢和去除杂原子的含钿和铇的层状硫化物. 首先, 我们综述了用扩展X射线吸收精细结构(EXAFS)和扫描透射电子显微 镜研究铂团簇生长和结构的最新研究动态. 详细讨论了氧化预处理条件以及氢气环境中的还原温度对铂纳米粒子形态的 影响, 并结合最近的实验结果进一步延伸对铂纳米颗粒结构演变的理解. 随后, 本文总结了一系列分析表征技术对层状硫 化物纳米颗粒研究的贡献, 综述了硫化物纳米粒子活性中心结构的研究进展, 重点介绍了边缘活性中心与硫和氢之间的互 动在化学吸附、物理吸附及溢流效应中的关键作用. 本文也对负载及非负载型的硫化物纳米粒子最新程序升温还原实验 结果进行了探讨. 氧化铝负载的硫化钿颗粒在程序升温还原过程中的结构变化可以通过EXAFS实验和密度泛函理论模拟 来解释. 研究表明, 可识别的硫化物边缘活性中心上硫原子的去除是导致这一类结构变化的主要原因.

关键词: 催化基础研究; 铂; 金属硫化物; 催化重整; 加氢处理

收稿日期: 2019-01-31. 接受日期: 2019-03-28. 出版日期: 2019-11-05.

*通讯联系人. 电子信箱: Qianjun.Chen@Honeywell.com

†共同第一作者.

本文的电子版全文由Elsevier出版社在ScienceDirect上出版(http://www.sciencedirect.com/science/journal/18722067).
\end{abstract}

